\title{
Privatizing Public Services and Strategic Behavior: The Impact of Incentives to Reduce Workers' Compensation Claim Duration
}

\author{
Melissa Mclnerney \\ The College of William and Mary
}

College of William and Mary

Department of Economics

Working Paper Number 88

Current version: May 2010

Previous version: August 2009

\footnotetext{
*I thank the Workers' Compensation Research Institute and Economic Club of Washington for financial support and individuals at the Ohio Bureau of Workers' Compensation for providing the administrative claims data and technical assistance that made this project possible. I am also grateful for the guidance provided by Judith Hellerstein, Mark Duggan, Bill Evans, Melissa Kearney, Jonah Gelbach, and Rick Victor, and comments given by Sarah Bohn, Maria Fitzpatrick, Judy Geyer, Melinda Sandler Morrill, and Sarah Pearlman.
} 
COLLEGE OF WILLIAM AND MARY

DEPARTMENT OF ECONOMICS

WORKING PAPER 88

May 2010

\title{
Privatizing Public Services and Strategic Behavior: The Impact of Incentives to Reduce Workers' Compensation Claim Duration
}

\begin{abstract}
During the 1990s, the state of Ohio contracted out Workers' Compensation (WC) case management, incorporating a large bonus payment intended to reward reduced claim duration. The bonus is essentially a decreasing function of average days away from work, excluding claims longer than 15 months. In response, duration is predicted to decrease for claims with moderate injuries and increase for some severe claims so that claimants miss more than 15 months of work and are excluded from the calculation. I find that contractors increased duration for severe claims but no evidence that contractors successfully reduced duration for moderate claims. However, contractors received large bonus payments. This is likely because the financial reward to merely excluding a small share of severe claims from the calculation of the bonus payment is large enough to enable TCMs to receive the full bonus. These contractor responses are inconsistent with state intentions, suggesting public entities should anticipate strategic behavior when crafting performance-based incentives.
\end{abstract}

JEL codes: H72, J28, L33

Keywords: Workers' Compensation, Contracting Out, Privatization

\author{
Melissa McInerney \\ Department of Economics, \\ College of William and Mary \\ Williamsburg, VA 23187-8795, \\ mpmcinerney@wm.edu
}


Privatizing Public Services and Strategic Behavior:

The Impact of Incentives to Reduce Workers' Compensation Claim Duration

\begin{abstract}
During the 1990s, the state of Ohio contracted out Workers' Compensation (WC) case management, incorporating a large bonus payment intended to reward reduced claim duration. The bonus is essentially a decreasing function of average days away from work, excluding claims longer than 15 months. In response, duration is predicted to decrease for claims with moderate injuries and increase for some severe claims so that claimants miss more than 15 months of work and are excluded from the calculation. I find that contractors increased duration for severe claims but no evidence that contractors successfully reduced duration for moderate claims. However, contractors received large bonus payments. This is likely because the financial reward to merely excluding a small share of severe claims from the calculation of the bonus payment is large enough to enable TCMs to receive the full bonus. These contractor responses are inconsistent with state intentions, suggesting public entities should anticipate strategic behavior when crafting performance-based incentives.
\end{abstract}

In recent decades, the public sector has privatized an increasing variety of services, ranging from public utilities in many developing countries to defense, prisons, schools, and social services in the United States. As the number of services subject to privatization grows, a key concern is how to best structure contracts to support programmatic goals and mitigate unintended consequences. In this paper, I study one such privatization effort, contracting out case management services in the state of Ohio's Workers' Compensation (WC) program-a large social insurance program that provides medical care and cash benefits to workers injured on the job. The contracts include a substantial performance-based component, and I show that the contractors respond strongly to the incentive structure. However, because of the nonlinear incentive structure, some responses are inconsistent with the state's intentions. In addition to documenting these unintended consequences, I also identify one mechanism the contractors use to carry out this strategic behavior. The conclusions of this analysis can inform other privatization efforts, especially those that evaluate contractors based on program recipient outcomes, as in social services.

In the United States, several social service programs have been subject to privatization, including welfare, job training, and WC. Contracts for these privatization efforts often incorporate a performance-based component rewarding program participant outcomes, such as leaving the welfare rolls, employment upon completion of job training, and the focus of this paper-reducing the amount of time injured workers spend away from work for WC. Previous work examining such privatization efforts primarily focuses on contracts that quantify performance using post-training wages or employment (e.g., Courty and Marschke, 2008; 
Heckman et al., 2002). These papers show that short-run outcomes improve in an effort to increase performance, as measured by the performance standards, but find no change in long-run outcomes. In this paper, I examine the impact of a different type of contract-one that rewards reductions in the duration of benefit receipt rather than post-program outcomes. Like welfare, injured workers receive WC benefits while out of work, so reducing duration will decrease program costs. Therefore, the findings from this analysis are directly applicable to evaluations of case managers in programs such as welfare or unemployment, other public programs that face higher costs when recipients receive benefits longer.

Similar to Unemployment Insurance, benefits and costs for WC vary across states, and state policymakers are concerned that high employer costs will make their state less attractive to business. Employer costs for WC rose by over 25 percent between 1987 and their peak in 1993. In response, many states passed policy reforms in an effort to reduce these employer costs. ${ }^{1}$ In this paper, I examine one such reform enacted by the state of Ohio; the state contracted out WC case management responsibilities to companies called Third-Party Case Managers (TCMs) with the hope that, as private companies, TCMs might be able to get injured workers back on the job more efficiently than if the state continued to manage WC claims. ${ }^{2}$

Two years after the TCMs were introduced in Ohio, the state incorporated a large bonus incentive payment intended to reward the TCMs for getting injured workers back on the job sooner. The impact of this bonus payment on claim duration is the focus of this paper. The exact structure of the payment is quite intricate, but it is essentially a decreasing function of average days away from work for claims meeting two criteria. First, the state selected a subset of detailed injuries to "incentivize," so a claim is only included in the payment calculation if the worker is diagnosed with one of the "incentivized" injuries. Second, a claim having an incentivized injury is excluded from the calculation of average days away from work if the injured worker does not return to his or her job within 15 months. As a result of this provision, the policy does not penalize TCMs for a particularly bad draw of claims. However, it gives TCMs a perverse

\footnotetext{
${ }^{1}$ Several different policies were enacted, some addressed employer costs directly by deregulating premiums or expanding opportunities for self-insurance. Other policies sought to decrease costs by reducing the total amount of benefits paid to injured workers, either by making it more difficult for benefits to be awarded or by attempting to get injured workers back to work sooner. Although there is some empirical evidence about the efficacy of these reforms (e.g., Boden and Ruser, 2003 and Neumark et al., 2007), these papers examine reforms that differ from the privatization intervention examined in this paper, and many unanswered questions remain.

${ }^{2}$ In Ohio and the larger WC community, TCMs are referred to as Managed Care Organizations (MCOs); however, I refer to them as TCMs to avoid confusion with health insurance MCOs, which are structured differently.
} 
incentive to actually increase duration for some claims with incentivized injuries so that the claimants miss more than 15 months and are then excluded from the calculation of average days away from work used to compute the bonus payment.

Therefore, the structure of the bonus payment suggests that a profit-maximizing TCM will react with heterogeneous responses as a claim develops over time. It takes an average of seven days after an injury for a TCM to learn of the claim from the doctor. So duration for shorter, less severe injuries that are resolved before one week passes should not differ for incentivized injuries. If the injured worker is still away from work when the TCM learns of the claim, the case manager will initially attempt to get the injured worker back on the job as soon as possible. The case manager will continue to endeavor to expedite return-to-work until the claim extends long enough that the claimant could feasibly remain out of work past 15 months. At this point, it is profitable for the TCM to extend the claim beyond 15 months so that it is excluded from the bonus payment calculation. One possible way a case manager might extend a claim is by enrolling the injured worker in vocational rehabilitation to re-train claimants for work.

To test whether the TCMs maximized the bonus payment by attempting to reduce duration for moderately severe claims and increasing duration for severe claims, I acquired administrative claims data for all claims occurring between 1995 and 2002. I use variation in the implementation of these policies over time and across injury to determine whether or not the policy changes have any impact on claim duration. The structure of the bonus suggests it will not have any effect on the most minor claims because these claimants return to work before the TCM becomes involved, and this is confirmed in the data. The case managers are predicted to successfully reduce duration for those claimants having moderately severe injuries because as soon as claims are filed, the injured workers are exposed to an aggressive return-to-work campaign. However, I find no evidence that the bonus induces TCMs to reduce duration of moderately severe claims; results from quantile regression confirm that duration does not increase for these claims. One reason TCMs may not have focused efforts on reducing duration for this group may be because the financial reward to keeping severe claims out of work longer-and out of the calculation of the bonus payment-is so large that TCMs did not need to get moderately severely injured claimants back to work sooner to receive the full bonus payment.

Duration is predicted to increase for claimants with severe injuries because claims lasting longer than 15 months are excluded from the calculation of the bonus payment. I test for this 
response in several ways and conclude the bonus increases duration for severe claims with incentivized injuries. Restricting attention to severe claims, I find that the bonus increases average days away from work by nearly three weeks for claims having incentivized injuries. I verify that this corresponds to the predicted strategic behavior on the part of the TCMs because the probability a claim spans more than 15 months rises by over 30 percent for claims having an incentivized injury. Since the most severe claims comprise a disproportionate share of program costs, the intended reduction in employer costs was not realized.

With the administrative data, I test one mechanism that case managers may use to influence claimants to remain out of work past 15 months_-vocational rehabilitation. On average, the timing of the program is consistent with its use as a method to strategically increase duration past 15 months, and incentives to employers and TCMs are consistent with increasing use of vocational rehabilitation. After the bonus is in place, claims having incentivized injuries are over fifty percent more likely to receive vocational rehabilitation.

I also estimate the overall effect of TCMs because it is possible that simply contracting out services impacted claim duration. To quantify this, I must assume that introducing TCMs was the only change to duration in Ohio between 1995 and 2002, an assumption that is unlikely to hold. Nevertheless, I find that after the TCMs began operation average duration fell for all minor claims, even if the claim had a non-incentivized injury. In total, although contracting out services to TCMs modestly reduces days away from work for the majority of minor claimants, the net result of the bonus payment is an overall increase in days away from work. I estimate the bonus payment costs the state over $\$ 8.5$ million per year in additional benefits paid.

\section{Workers' Compensation, Third-Party Case Managers, and the Bonus Payment}

\subsection{Workers' Compensation Insurance}

States mandate that employers provide WC insurance at the benefit levels set by each state. Employers may purchase WC insurance from private companies, from the state, or, if the company is large enough, the employer may self-insure. ${ }^{3}$ Nationwide, approximately 50 percent of benefits are paid by private insurers, and state insurers and self-insured employers each pay 25

\footnotetext{
${ }^{3}$ If an employer purchases WC, the premiums are an increasing function of how risky the employer's business is (base premium) and the employer's loss history (experience rate). Smaller employers simply pay these base premiums, and WC premiums are experience rated for larger or riskier employers.
} 
percent (Sengupta et al., 2009). ${ }^{4}$ In five states, including Ohio, private insurance is not offered so all smaller employers purchase public insurance and larger employers may self-insure. ${ }^{5}$

WC claims fall into two categories: "medical only" or "cash benefits." A worker is injured on the job and seeks medical care from a doctor who certifies that the injury is workrelated. Those claimants who only receive medical care and return to work within one week are called medical only recipients. Claimants missing more than one week of work receive both medical care and cash benefits and are labeled cash benefit recipients. Although only 20 percent of claims receive cash benefits, they incur nearly 95 percent of benefits-medical care and cash payments. Furthermore, costs are concentrated in a fraction of the cases; 35 percent of cash beneficiaries are responsible for 80 percent of costs (Sengupta et al., 2009). Therefore, the most productive efforts to reduce benefits paid will target particularly severe claims.

Payments cease when the injured worker heals and returns to work. ${ }^{6}$ Conflicting motives regarding claim duration make it difficult for injured workers, employers, insurers, or state policymakers to influence when a claim will end. A worker who values leisure may wish to remain out of work longer when benefits are more generous (Butler and Worrall, 1985; Krueger, 1990; Meyer et al., 1995; and Neuhauser and Raphael, 2004). Employers and insurers desire shorter claims to reduce costs, and states seek a balance between lowering employer costs and protecting injured workers. The employer may attempt to expedite return-to-work by finding ways to accommodate a recovering worker in the workplace (Krueger, 1991). Insurers may directly encourage the worker to go back to work and offer employers suggestions for how an injured worker might be accommodated in the workplace. The state may attempt to expedite this process by implementing policies to reduce claim duration, such as mandating TCMs. During the 1990s, many states enacted WC policy reforms intended to reduce employer costs, and the introduction of TCMs in Ohio was the largest statewide effort to reduce claim duration.

\subsection{Third-Party Case Managers and Ohio}

TCMs are private companies that assume WC case management responsibilities; they are used nationwide to reduce employer costs by facilitating return-to-work for injured workers. TCMs are especially popular among employers that self-insure WC because they eliminate in-house

\footnotetext{
${ }_{5}^{4}$ In states that offer all three forms of insurance, only employers with poor loss histories acquire public insurance.

${ }^{5}$ The five states are Ohio, North Dakota, Washington, West Virginia, and Wyoming.

${ }^{6}$ In some cases, the worker only heals partially and returns to work in a restricted capacity or is permanently disabled and receives permanent benefits.
} 
claims management. In Ohio, TCMs currently manage every claim insured by the state. The TCMs were implemented in Ohio in two phases, as shown in Figure 1. In 1997, the state contracted out case management services to TCMs in hopes of curbing employer costs. Case management involves medically managing a claim and expediting return-to-work. ${ }^{7}$ The TCMs began operation in 1997, and by the beginning of 2007 there were 27 TCMs, with four of them managing 70 percent of claims (Ohio Bureau of Workers' Compensation, 2008). ${ }^{8}$

The TCMs are mandated to provide insurance cards to every employer whose claims they manage. After an injured worker informs his or her employer of the injury, the employer gives the injured worker a TCM insurance card identifying which TCM manages the claim. An injured worker then receives care from any doctor of his or her choice. The TCM insurance card informs the doctor's office where to file the claim and submit the bill. The introduction of these insurance cards alone may streamline the path between injury and the first doctor's appointment, and this may reduce average duration for all minor claims, whether or not the claim has an incentivized injury. The doctor makes a diagnosis and assesses if the injury is work-related. The physician then reports the claim to the employer's chosen TCM. After an average of seven days, the TCM learns of the claim, reports it to the state, and assigns a case manager. At this point, the case manager is required to contact the doctor, the employer, and the injured worker to manage the claim and acquire the necessary information to verify the injury and confirm it is work-related.

After these contacts, the case manager may attempt to reduce claim duration. According to individuals at some of Ohio's largest TCMs, the organizations use three strategies to decrease days away from work. First, case managers encourage aggressive medical treatment, in which workers are treated and returned to work as soon as possible. Second, case managers monitor injured workers in an effort to get the claimants to return to work sooner and reduce moral hazard. Third, case managers encourage employers to accommodate injured workers on the job.

At each medical appointment for a work-related injury, the doctor fills out a form identifying the activities the claimant is released to do. Within the restrictions outlined on this form, the case manager helps the employer identify ways the injured worker might be useful in the workplace. For example, a nurse's aide who suffers from a back injury might be released to

\footnotetext{
${ }^{7}$ In Ohio, medical management of a claim consists of filing the claim with the state, providing initial approval of requested medical procedures, and directing state reimbursement to medical providers.

${ }^{8}$ They are CareWorks, CompManagement HealthSystems, GatesMcDonald HealthPlus, and Sheakley UNICOMP. Employers pay premiums to the state but select which TCM will manage their claims every two years. Initially, the state compensated TCMs as a function of the total premiums managed by the TCM.
} 
do seated work that does not require lifting more than ten pounds, such as folding towels or clerical work. There is suggestive evidence that employer efforts to provide modified work or light duty to a recovering worker successfully reduces claim duration. Using administrative claims data from Minnesota, Krueger (1990) shows that duration is shorter for employees whose employer is self-insured and not privately or publicly insured. Since self-insured employers bear the full cost of each claim, they may be more likely to offer modified work or more closely monitor a worker's recovery. This result suggests that case managers could successfully reduce claim duration by facilitating return-to-work with employers. If the claimants cannot return to their former positions, the TCM might advocate vocational rehabilitation benefits.

\subsection{The Return-to-Work Bonus Payment}

Two years after the TCMs were implemented, the state restructured TCM compensation to incorporate a performance-based component, the bonus payment. The impact of the bonus payment on claim duration is the focus of this paper. The bonus was intended to reward TCMs for effectively reducing claim duration. ${ }^{9}$ It is paid each quarter and is essentially a decreasing function of average days away from work for eligible claims, subject to a maximum. The bonus payment comprises over forty percent of TCM compensation, approximately $\$ 70$ million in FY 2004 (Ohio Bureau of Workers' Compensation, n.d.). ${ }^{10}$ Figure 2 depicts the share of TCMs receiving the bonus payment in each quarter since its inception. As is clear from the figure, TCMs responded to the incentives inherent in the program. The solid line depicts the share of TCMs receiving any bonus payment, and the dashed line plots the share of TCMs receiving the full bonus payment. Within three calendar quarters, nearly all TCMs began to receive some bonus payment, and over half of all TCMs received the maximum amount. This pattern of bonus payment receipt may arise because TCMs reduced claim duration, the intended effect.

Alternatively, a large share of TCMs might qualify for the bonus if the minimum level of performance required to receive the bonus was set relatively low (Heinrich and Choi, 2007). I examine this issue in the empirical analysis.

A claim must meet two criteria to be included in the calculation of days away from work for the bonus payment. The injured worker must have been diagnosed with an incentivized injury and the injured worker must return to his or her job within 15 months. Five-digit ICD-9 codes are

\footnotetext{
${ }^{9}$ The TCMs were aware that the structure of compensation would incorporate a performance-based component, but the exact structure of the bonus payment was not known to TCMs until 1999.

${ }^{10} 2006$ MCO Agreement. Appendix E, page 13. Acquired from a public records request.
} 
the detailed injury codes used internationally by doctors to diagnose patients, and the codes are so detailed that at least 22 codes describe pain in the back or neck. Some of these codes correspond to common workplace injuries for which it is straightforward to identify a goal or benchmark number of days away from work. For example, it is much easier to identify optimal duration for injured workers suffering from superficial cuts than for traumatic head injuries. ${ }^{11}$ Therefore, to facilitate performance-based evaluation of TCMs with different injury mixes, the state chose to incentivize 266 detailed ICD-9 codes with well-defined benchmarks. Only claims having one of these diagnoses or injuries are included in the calculation of the bonus payment. ${ }^{12}$ In Table 1, I present detailed injury codes by incentivized status for the 20 most common injuries in each category. This table shows the level of detail of the injury codes and that many types of injuries are common to both groups, such as back sprains, bruises, and cuts.

Claims also must meet a second criterion to be included in the bonus payment. A claim having an incentivized injury will be excluded from the calculation if the injured worker does not return to work within 15 months. ${ }^{13}$ This provision effectively shelters TCMs from a particularly bad draw of claims, but also creates a perverse incentive for TCMs to increase the duration of some claims to ensure they are not included in the calculation of the bonus payment. Suppose $a$ is the mean days away from work for the claims used to compute a TCM's bonus payment and $b$ is the mean of the benchmarks corresponding to these injuries. The bonus payment is a decreasing function of $a-b$. The lower a TCM's actual experience $(a)$ is relative to the goal for that TCM $(b)$, the higher the bonus payment. ${ }^{14}$ Therefore, a TCM can lower mean days away from work $(a)$ by ensuring those claims that could feasibly result in a loss of more than 15

\footnotetext{
${ }^{11}$ These benchmarks are not available through public records requests from the state because they are proprietary. They were derived from Milliman and Robertson, Healthcare Management Guidelines, Volume 7.

${ }^{12}$ The conditions were also selected because there were enough claims for each injury prior to the incentive implementation to construct the mean number of days missed by workers having such conditions.

${ }^{13}$ In practice, the incentive is more complex as it is based on quarters of the calendar year, reflecting the return-towork experience of the previous five quarters. For example, the incentive payment for Q1 in 2007 is based on spells that began and ended between Q4 2005 and Q4 2006. Consider injuries occurring in Q4 2005; these injuries must return to work before January 1, 2007 to be included in the incentive payment. Thus, an injury occurring on October 1, 2005 must miss 15 months of work before it is excluded from the average calculation. In contrast, an injury occurring on December 31, 2005 must only miss 12 months of work before being excluded from the calculation. I refer to this provision as " 15 months" for simplicity but incorporate this complexity in my empirical work.

${ }^{14}$ To be precise, the incentive $=\max (0, \mathrm{f}[(a-b) /(c-b)])$ where $a=$ actual average days away from work, $b=$ average benchmark days away from work, $c=$ average counterfactual days away from work, and $f$ is a decreasing function of $[(a-b) /(c-b)]$. Each quarter, average days away from work are computed for claims having one of the "incentivized" conditions and that began and ended within the past 15 months. The state also computes average corresponding benchmark (b) and counterfactual (c) days away from work for the injuries included in that quarter's payment.
} 
months of work in fact remain out of work so long they are not included in the bonus payment. ${ }^{15}$ In practice, many TCMs use data management systems that provide case managers with information about how a particular claim is doing relative to the bonus payment. The data management system tracks information such as how much time the claimant has missed from work and provides information about what the relevant benchmarks are for the injured worker's diagnosis. Therefore, individual case managers have a great deal of information at their disposal to evaluate how a claim is doing relative to the benchmark.

Heinrich and Choi (2007) expand the theoretical framework describing government contracts to include performance based bonus payments. They argue that gaming will be even more severe if contractors can achieve a high level of performance at a low cost. The above discussion suggests that the bonus payment for Ohio TCMs is structured in this way; TCMs can achieve a high level of performance (low average days away from work) at a low cost (not by reducing days away from work, but by increasing days away from work for some particularly severe claims). In the next section, I use administrative claims data to quantify TCM responses.

\section{Data and Econometric Approach}

\subsection{Data Description}

To assess the impact of the bonus payment intended to reduce WC claim duration, I acquired administrative claims data from the Ohio Bureau of Workers' Compensation, the state insurer. The dataset includes information on all injuries occurring between January 1, 1995 and June 30, 2002 and follows each claim for three years. For each claim, the dataset contains information on days away from work, the diagnosis for the injury (five-digit ICD-9 code), demographic characteristics (age, sex, and marital status), job characteristics (1-digit industry and 1-digit occupation), and identifiers for the employer and the TCM. I exclude observations that are missing data or where the injured worker received a death benefit, permanent disability award, or lump-sum settlement within three years of the injury. ${ }^{16}$ The extent of these sample restrictions on the data is shown in the first six rows of Table 2.

\footnotetext{
${ }^{15}$ For a more formal discussion, see McInerney (2008).

${ }^{16}$ By law, claimants awarded either death or permanent total disability benefits are excluded from the incentive calculation. $2006 \mathrm{MCO}$ Agreement. Chapter 2, page 54. Claims receiving permanent partial disability benefits or lump sum settlements are excluded because receipt of these benefits does not depend on whether or not an individual is working. Therefore, I cannot infer when the injured worker returned to work. Incentives regarding when to close such claims are the same as for all other cash benefit claims.
} 
I also drop claims that are missing return-to-work information. This exclusion demands careful treatment because it differentially impacts medical only claims, those claims that return to work within one week and do not receive cash benefits. For claimants receiving cash benefit payments, the state maintains a complete transaction history that details each cash payment made to a claim. This file quantifies the type of payment made and the dates covered by each check. I assume cash benefit claimants return to work when benefits cease. ${ }^{17}$ Between 28.1 and 28.6 percent of cash benefit claims having incentivized injuries are missing return-to-work information, and this information is missing for between 34.3 and 39.0 percent of nonincentivized injuries. Thus, the rate of missing data for cash benefit claimants is roughly constant over the three time periods and assumed to be missing at random. ${ }^{18}$

In contrast, instances of medical only claims missing return-to-work information pose a much more nuanced problem for analyzing the impact of the bonus payment on days away from work. By definition, medical only recipients never receive cash benefit checks, so a separate file captures the date each worker actually returns to his or her job. Before the implementation of the bonus, the state insurer simply needed to verify claimants did not miss more than one week of work. After the bonus was put in place, it became much more important for the state to capture return-to-work information for medical only claims with incentivized injuries because the days away from work for these claims were now used to calculate the bonus payment. Consistent with these incentives, the share of medical only claims with incentivized injuries missing return-towork data fell once the bonus is in place (from 50.8 percent to 9.3 percent). In contrast, the corresponding decline among non-incentivized injuries was somewhat smaller. Before the bonus was in place, 50.0 percent of medical only claims having non-incentivized injuries were missing return-to-work data. Once the bonus was implemented, the share of these claims that were missing data fell to 11.8 percent, a slightly smaller reduction. Return-to-work information is not missing at random for medical only claims. Failing to account for this non-randomness would

\footnotetext{
${ }^{17}$ This is a nontrivial assumption, but it is confirmed in the data. For 94 percent of cash benefit claimants, I have two sources of return-to-work information. In addition to the complete transaction history of all cash benefit payments, recipients also appear in a file of return-to-work dates (1.4 percent are assumed to be censored because they receive benefits continuously for five years and return-to-work dates are missing for the remaining 5 percent). For 86 percent of those cash benefit claimants with both sources of information, the return-to-work date is the same as that constructed by the cessation of benefits. Furthermore, the main results of the paper are upheld when I drop those non-censored cash benefit claimants missing return-to-work information or whose information is incongruent. ${ }^{18}$ I selected a random sample of claims and compared them with the OH BWC database to confirm that return-towork information is complete for the claims reporting it, but missing at random, at least based on observable worker and injury characteristics, for claims without any return-to-work information.
} 
result in a sample of claims comprised of relatively more medical only claims. Since medical only claims are shorter in duration, the changing sample composition will drive a mechanical decline in days away from work in the empirical results. Therefore, I weight all results by the inverse probability that a claim has valid return-to-work information. ${ }^{19}$

I make the final two restrictions so that the different specifications are computationally feasible. Claims are preserved only if the injury designation appears in each of the three time periods (before the TCM is introduced, once the TCM is managing claims but before the bonus is implemented, and the period when the TCM and bonus are both in place). This restriction accomplishes two things; it drops the injuries with the fewest number of claims and ensures the sample of injuries is the same in each period. ${ }^{20}$ I further restrict the sample to those injuries that have more than 100 claims in each period. ${ }^{21}$ The final baseline sample has 475,974 observations.

\subsection{Descriptive Statistics}

Table 3 contains descriptive statistics for the outcome of interest, days away from work, separately for claims with incentivized injuries (treatment group) and non-incentivized injuries (comparison group). The first striking thing about this comparison is that average duration is quite different for the two groups. Claimants having non-incentivized injuries return to work in an average of about four days. This is much more quickly than average return-to-work for claimants having incentivized injuries, who return to work in an average of about one and a half weeks. This suggests the state may have chosen to incentivize the most costly workplace injuries. Although this may be a desirable policy, it means that non-incentivized injuries might not be an ideal comparison group. I also conduct the analysis separately for the three most common types of injuries: back sprains, bruises, and cuts. Within the samples of bruises and cuts, mean days away from work are rather similar for both incentivized and non-incentivized injuries.

To illustrate that changes in days away from work were heterogeneous and timed with the bonus payment's implementation, Figures 3a-3c depict changes over time for selected quantiles of the weighted distribution of claim duration, separately for claims having incentivized and non-

\footnotetext{
${ }^{19}$ I estimated this using a linear probability model where the dependent variable is equal to one if an observation has valid return-to-work information controlling for demographic characteristics, employer controls, TCM fixed effects, and injury indicators. These covariates are allowed to vary by (1) whether or not the claim has an incentivized injury, (2) when the injury occurred (PRE, POST1, POST2), and (3) whether or not the claim received medical only or cash benefits. Claims with valid return-to-work information are preserved in the final sample.

${ }^{20}$ There are 597 diagnosis codes with fewer than three claims. By definition, this restriction drops these injuries.

${ }^{21}$ The main results are not sensitive to this restriction; results are qualitatively similar when the sample is cut to preserve injuries with at least 25 or 500 injuries each period.
} 
incentivized injuries. The first vertical line marks the quarter when the TCMs began managing claims (1997, Q1), and the second vertical line marks the quarter when the bonus payment was implemented $\left(1999\right.$, Q2). For claims in the $90^{\text {th }}$ and $95^{\text {th }}$ percentiles, days away from work range from four to 29 days, and fell slightly for all claims once TCMs began to manage claims. After the bonus was put in place, there was no additional decline in days away from work for claims having incentivized injuries. However, the $99^{\text {th }}$ percentile follows a totally different pattern. Once the bonus payment was introduced, the duration of claims with incentivized injuries increased dramatically. The descriptive statistics suggest that increases in duration were concentrated among the top one percent of all claims. Although a small share of all claims, these injuries comprise a substantial share of WC costs. For example, approximately 70 percent of all cash benefits were paid to injured workers at or above the $98^{\text {th }}$ percentile, and over half of all cash benefits accrued to injured workers at or above the $99^{\text {th }}$ percentile.

One mechanism TCMs might use to increase duration is enrollment in vocational rehabilitation. As shown in Figure 4, there was a large, statistically significant increase in vocational rehabilitation receipt among claims having incentivized injuries, and this increase in vocational rehabilitation was timed with the policy change.

These changes observed in the descriptive data are consistent with the policy reforms having a measurable effect. However, it is also possible the observed patterns are caused by changes in the composition of injured workers; therefore, it will be important to carefully control for injury composition when analyzing the impact of the policy changes on claim duration. In the next section, I turn to a formal analysis of claim duration as a function of the policy changes, controlling for a worker's injury, demographic, and job characteristics.

\section{Measuring the Impact of the Return-to-Work Bonus Payment}

The basic empirical strategy I employ compares the change in days away from work arising from the implementation of the bonus payment for claims having an incentivized injury (treatment group) with the change in duration over the same period for claims not having an incentivized injury (comparison group). I include claims not having incentivized injuries to capture any underlying trends over time in days away from work so that I can better isolate the impact of the bonus payment. The identifying assumption that will lead me to draw a correct causal interpretation of the results is that any trend influencing claim duration has the same effect on days away from work for claims having incentivized and non-incentivized injuries. This is a 
nontrivial assumption because different types of injuries are granted incentivized or nonincentivized status, and mean duration is different for the two groups. Therefore, any changes that may differentially impact claims of longer duration may violate this assumption. For example, between 1997 and 2002, Ohio employers had reduced reason to reduce claim duration. During this period, employers received large dividend payments from the state insurer, in some years, these dividends were worth at least 75 percent of employer premiums. ${ }^{22}$ Thus, employers were sheltered from the full impact of a claim on their experience rating-and WC premiums.

I address these issues in two ways. First, I can quantify whether or not the comparison group reasonably controls for other trends by testing whether the two groups receive similar treatment in the period before the bonus payment was in place. Between 1997 and the bonus payment's implementation in 1999, the TCMs had no reason to treat workers with the two classes of injuries any differently from one another. Therefore, I test whether or not the two groups received equal treatment during this period. Second, I examine the main results within four samples of more comparable injuries.

I investigate whether or not the observed changes in mean days away from work persist once I control for injury, demographic, and job characteristics. Using Ordinary Least Squares, I estimate days away from work using the following specification:

(1) DAYS $_{i, j, t}=\lambda_{0}+\lambda_{1}$ POST1 $_{t}+\lambda_{2}$ POST $_{t}+\lambda_{3}$ POST1 $_{t} *$ INCENT $_{j}+\lambda_{4}$ POST $_{t} * I N C E N T_{j}+\beta X_{i}+\gamma_{j}+\eta_{t}+\mu_{i, j, t}$

where $i$ references the claimant, $j$ the diagnosis, and $t$ the year of injury. ${ }^{23}$ Days away from work is a function of having an injury which will qualify for the bonus, captured in the vector of diagnosis code fixed effects $\gamma$; an indicator for the period when the TCMs are in place but the bonus is not, POST1; and an indicator for the second policy change when the TCM and the bonus are both in place, POST2. ${ }^{24}$ Let INCENT identify those claims assigned one of the 266 incentivized codes. ${ }^{25}$ The interactions between POST1*INCENT and POST2*INCENT are the main variables of interest. The vector $X$ includes job and demographic characteristics, as well as

\footnotetext{
${ }^{22}$ Personal Communication, Elizabeth Bravender, Ohio Bureau of Workers' Compensation, August 3, 2006.

${ }^{23}$ The main qualitative results are confirmed using a Cox proportional hazard analysis. To address the skewness of the data, I also estimated negative binomial models. The general conclusions of the paper are upheld in these models, even on the sample of all injuries. Results available upon request.

${ }^{24}$ In this case, the left out category is PRE, the period before the TCMs are in place (1/95-2/97).

${ }^{25}$ The variable INCENT is not included by itself because it is perfectly correlated with $\gamma$.
} 
month indicators to control for the seasonality of workplace injuries. ${ }^{26}$ The vector $\eta$ contains year fixed effects. Standard errors are clustered by injury code.

The estimates for $\lambda_{1}$ and $\lambda_{2}$ capture the impact of the TCMs in POST1 and POST2 on all claims, and I expect the coefficients will be zero or negative. The policy changes are only predicted to impact claims with non-incentivized injuries through infrastructure changes, such as the TCM insurance cards. These infrastructure changes are likely to have a negative effect on the duration of claims having minor injuries. The coefficients $\lambda_{3}$ and $\lambda_{4}$ capture any average differential impact of the TCMs on claims having incentivized injuries. Since the TCMs were in place for two years before the bonus was implemented, I can check the assumption that the comparison group reasonably controls for other trends by examining claim duration for the two groups during this intermediate period. A priori, the introduction of the TCMs, without the bonus in place, is not predicted to have a differential impact on treatment group claims. If this is the case, the coefficient on POSTI*INCENT will be zero. In general, if the bonus induces treatment group claimants to return to work more quickly (slowly) on average, the coefficient on POST2*INCENT will be negative (positive).

Results for the full sample of claims are presented in Table 4, Panel A. I find no overall impact of the TCMs or the bonus payment on the full set of claims. This is not surprising because the full sample includes claims for which duration is expected to decrease as well as claims for which duration is expected to increase. Therefore, in the next section, I examine changes in duration separately for medical only and cash benefit claims. I split the sample in this way for two reasons. First, the policy changes are predicted to have different impacts on these two groups of claims. Since TCMs do not learn of claims until an average of one week has passed, the only impact on medical only claims will be changes in infrastructure. In contrast, TCMs are predicted to respond to the bonus payment and impact the duration of cash benefit claims. By splitting these two groups, I can separate the impact of infrastructure changes from the bonus payment. Second, cash benefit claims drive WC costs and most WC research exclusively looks at this subset of claims (e.g., Krueger, 1990; Meyer et al., 1995).

\subsection{Minor Claims}

\footnotetext{
${ }^{26}$ The job characteristics are 1-digit industry, 1-digit occupation, the employer's experience rate in the year of injury, and indicators for whether or not the employer is large or risky enough to be experience rated.
} 
I first examine the impact of the TCM and bonus payment on minor, medical only claims using the specification given in equation (1) for the sample of medical only claims. Infrastructure changes are predicted to reduce duration for all claims, so I expect to find a negative coefficient estimate on both POST1 and POST2. Since most claims are not filed with the TCMs until one week passes, I expect to find no differential impact for incentivized injuries. The results from this exercise are shown in Panel B of Table 4. The coefficients on POST1 and POST2 are statistically significant, near -.3, suggesting the TCMs reduced duration by about one-third of a day for all minor claims (compared with duration for all minor claims in the PRE period). This interpretation assumes that the only change to duration over this time period were the TCMs. In general, the coefficients on the interaction terms POST1 *INCENT and POST2*INCENT are small in magnitude and not statistically significant. This is expected because medical only claimants return to work before the claim is filed, so TCMs cannot differentiate between the two groups of claims. The one exception is found in the sample of cuts; however, although the coefficients are statistically significant, they are not economically meaningful. The coefficient estimates imply workers return to their jobs between .02 and .04 days sooner.

\subsection{Moderately Severe Claims and Severe Claims}

Next, I estimate days away from work as a function of the policy changes on the sample of cash benefit claims. Once the bonus is in place, the TCMs are expected to attempt to reduce claim duration for each claim with an incentivized injury until the claim exceeds the threshold at which point duration is predicted to increase. These regressions assume a common effect of the bonus payment on incentivized cash benefit claims of all levels of severity (relative to non-incentivized claims during this same time period), captured by the sign of the coefficient on POST2*INCENT. The expected sign is theoretically ambiguous because the TCMs are predicted to reduce duration for some cash benefit claims and increase duration for others.

These results are presented in Panel C. There is variation in mean days away from work among the different samples. Clearly, the cuts and bruises that receive cash benefits are less severe than the average back sprain. In every column, the coefficients on POST1 and POST2 are not statistically significant, suggesting there is no general effect of the TCMs on cash benefit claims. In column (1), using the entire stock of injuries, the coefficient on POST1 *INCENT is 4.45 but not statistically significant. This is consistent with incentivized injuries and nonincentivized injuries receiving the same treatment from the TCMs in the period before there 
bonus payment was implemented. When the sample is restricted to more similar groups of injuries, as in columns (2) through (5), this coefficient estimate is always small in magnitude and never significant. Therefore, the TCMs do not treat claimants having incentivized injuries any differently before the bonus is in place. In general, the coefficient on POST2*INCENT is large, statistically significant, and an order of magnitude larger than the POSTI*INCENT effect. In the common injury sample, the coefficient estimate for POST2*INCENT is 17.1, implying that implementing the bonus payment increased duration for incentivized injuries by nearly 2.5 weeks, relative to duration for non-incentivized claims during that same time period. ${ }^{27}$

The exception is found in the sample of cuts, a group of injuries expected to be unresponsive to TCM efforts. Among cuts, the estimates for the policy variables are never statistically significant, suggesting the policies had no effect on claimants with that group of injuries. This result is consistent with the previous literature which has found that claimants suffering "traumatic" injuries, such as cuts or fractured legs, are considered less responsive to changing benefit levels than claimants with soft tissue injuries (e.g., Biddle and Roberts, 2003; Biddle, 2001; Ruser, 1998; and Neuhauser and Raphael, 2004). If claimants are less sensitive to benefit levels, they will also likely be less responsive to TCM intervention.

The finding of an increase in days away from work among incentivized cash benefit injuries is consistent with TCMs increasing duration for particularly severe claims with incentivized injuries to maximize the bonus payment. However, this finding does not show directly that these increases correspond to claims becoming longer than 15 months. Moreover, this finding provides no evidence of the impact of the TCMs on moderately severe claims.

Following Meyer et al. (1995), I examine these differential responses using quantile regression estimates analogous to equation (1). Quantile regression allows me to estimate the impact of the bonus payment at different points in the response distribution, conditional on the covariates. There is so little variation in days away from work at the bottom of the distribution of claim duration (among medical only claims of one week or less) that it is only interesting (and feasible) to examine the results across quantiles for cash benefit claims. If the bonus induces TCMs to attempt to reduce duration for moderately severe injuries, then the coefficient on

\footnotetext{
${ }^{27}$ Over time, claims are less likely to be awarded cash benefits. If the probability of receiving cash benefits changes differentially for incentivized injuries, then the estimated coefficients on POSTI*INCENT and POST2*INCENT are biased away from zero. Results from a linear probability model of cash benefit receipt suggest the cleanest test is among common injuries. Results available upon request.
} 
$P O S T 2 * I N C E N T$ will be negative for the lower quantiles. Once duration exceeds the threshold beyond which it benefits the TCM for the claim to extend more than 15 months, the bonus should lead to either no change or increased duration. Thus, I expect the coefficient on POST2*INCENT will be large and positive for the higher quantiles.

The estimated coefficients for POST1 and POST2 are small in magnitude and generally not statistically significant, suggesting that even when the effect of TCMs is allowed to vary at different points on the distribution of claim duration, the TCMs had no overall effect on claims. ${ }^{28}$ The key results from quantile regression are shown in Figures 5a and 5b. In Figure 5a, the solid line depicts the coefficient on POST1 ${ }^{*} I N C E N T$ from 20 quantile regressions on the sample of cash benefit claims, from the $5^{\text {th }}$ through the $95^{\text {th }}$, and also including the $99^{\text {th }}$. The outer dashed lines bound the 90 percent confidence interval. The change in days away from work is always close to zero and is never statistically significant. The results are quite different in the analogous plot for the coefficient on POST2*INCENT, as shown in Figure 5b. Below the $30^{\text {th }}$ percentile, the coefficient is negative but not statistically significantly different than zero. Somewhat surprisingly, this result does not reflect the predicted decline in duration for moderately severe claims. Instead, it suggests there was no change in duration for these claims. From the $30^{\text {th }}$ to the $75^{\text {th }}$ percentiles, the coefficient is positive, between .16 and 5.51 , but still not statistically significantly different than zero. Between the $75^{\text {th }}$ and $95^{\text {th }}$ percentiles, the coefficient is positive and statistically significant, between 8 and 25 days. These findings are consistent with the bonus increasing duration for claims that exceed the 15-month threshold. However, these estimates do not allow me to pinpoint whether the observed increase reflects this strategic behavior because quantile regression describes changes to the response distribution, conditional on covariates. ${ }^{29}$

The evidence to this point suggests that TCMs are satisfying the conditions of the bonus payment by keeping injured workers out of work long enough to exclude them from its calculation, duration is falling by about one third of a day for all minor claims, but TCMs are not reducing duration of moderately severe claims. In the next section, I investigate whether or not claims are strategically getting longer so that they are excluded from the computation of the average days away from work and quantify the financial impact of such.

\footnotetext{
${ }^{28}$ The coefficient on POST2 is only statistically significant at the $10^{\text {th }}$ percentile, and the coefficient on POST1 is only statistically significant at the $10^{\text {th }}, 15^{\text {th }}$, and $25^{\text {th }}$ percentiles. In every case, the magnitude is small (less than 2 ). ${ }^{29}$ It is not so easy to determine what level of duration is represented by the $95^{\text {th }}$ percentile, conditional on all of these covariates. Each regression includes controls for demographic, employer, and job characteristics, and injury effects.
} 


\subsection{Strategic Behavior to Increase Duration}

To investigate whether or not claims are strategically getting longer so that they are excluded from the computation of average days away from work, I estimate the following linear probability model

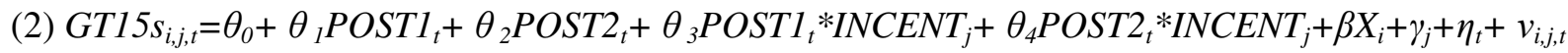

where GT15 is a dummy variable that equals one if the spell spans more than 15 months. If the increase in duration corresponds to strategic behavior to maximize the bonus payment, then I expect the coefficient estimate for POST2*INCENT to be positive and the coefficients on the other policy variables to equal zero. In Table 5, I present these results for corresponding samples of samples of cash benefit claims; results from probit models are qualitatively similar. In each case, the coefficients on POST1 and POST2 are small in magnitude and not statistically significant, implying the TCMs did not increase claims beyond 15 months indiscriminately. The coefficient on POSTI *INCENT is always small in magnitude and only statistically significant in the case of back injuries, -.002. This estimate implies once the TCMs are in place, workers having incentivized back injuries were 2 percentage points less likely to have a claim exceed 15 months. From a base of 4.3 percent of the sample having claims so long they exceed 15 months, this implies a 5 percent drop in the probability a claim exceeds 15 months. This could mean TCMs successfully reduce moral hazard among injured workers with back sprains in the period before the bonus is in place, or the drop may merely reflect the sample composition changes.

With the exception of the laceration sample, the coefficient on POST2*INCENT is positive and significant. For example, in the sample of common injuries in column (2), the estimate is .016. This implies that injured workers diagnosed with an incentivized injury are 1.6 percentage points, or 46 percent, more likely to be out of work for more than 15 months once the bonus is in place, suggesting TCMs engaged in strategic behavior to maximize the bonus. ${ }^{30}$

Although no single specification allows me to quantify the TCM response across the entire distribution of claim duration, together these estimates describe the impact of the bonus on claim duration for workers with claims of different severity. It appears that with regard to the most severe claims, TCMs are acting in ways consistent with maximizing the bonus payment. Yet I find no evidence that the bonus payment induces moderately severely injured claims to

\footnotetext{
${ }^{30}$ Cox proportional hazard model estimates with time varying covariates for incentivized, cash benefit injuries show that once the bonus is in place, the probability of returning to work declines the week before the 15 month threshold.
} 
return to work more quickly. At first, it seems somewhat surprising that since the fourth quarter of 2001, over 75 percent of all TCMs have received the full bonus payment each quarter.

However, a back of the envelope calculation shows that TCMs are able to have a large impact on the bonus payment by moving only a small number of severe claims past 15 months. Using the sample book of claims from the state's contract with TCMs, I calculate that moving one additional claim beyond 15 months increases the bonus payment by nearly $\$ 5,000$. Estimates of the number of claims TCMs move beyond 15 months in response to the bonus payment suggest that moving a small number of claims beyond 15 months yields a large financial reward. For the sample of all claims (medical only and cash benefit), I estimate that the bonus yields a .11 percentage point increase in the likelihood a claim exceeds 15 months. This increase corresponds to moving 5 claims past 15 months for the smallest TCMs, and moving between 460 and 840 claims past 15 months for the largest TCMs. Although I find no evidence that TCMs are reducing duration for moderately severe claims, these calculations illustrate that by increasing duration for particularly severe claims, TCMs are able to increase the bonus. ${ }^{31}$

Although TCMs are not behaving in ways envisioned by the state when the bonus was constructed, TCM responses are consistent with the expected effects given the structure of the bonus payment and theory governing performance-based bonus payments (Heinrich and Choi, 2007). These results do not offer explanations for the mechanism used to impact duration. To address this, in the next section I explore one potential mechanism through which case managers might be able to impact duration.

\section{Exploring How TCMs Achieve Results}

One method case managers might use to extend claim duration past 15 months, so that the claim will no longer be included in the bonus payment calculation, is to enroll claimants in vocational rehabilitation programs. Vocational rehabilitation consists of job training and a formal job search in preparation for gainful employment in a new position. Financial incentives to workers, employers, and TCMs are consistent with its use as a means to increase duration. In Ohio, injured workers continue to receive WC cash benefits while enrolled. ${ }^{32}$ In addition, TCMs also

\footnotetext{
${ }^{31}$ This implies that to maximize the bonus payment, TCMs can direct their case managers to operate under one of two assumptions. At first, TCM case managers do not work to reduce duration. However, once the claim approaches 15 months, the case manager will begin to consider options such as vocational rehabilitation.

${ }^{32}$ For this mechanism to be effective, the injured workers must choose to participate in the program. Aakvik and Kjerstad (2003) provide the best estimates of the determinants of participation in Norwegian vocational rehabilitation programs. They find displaced workers are more likely to participate in vocational rehabilitation
} 
have two financial incentives to enroll workers in vocational rehabilitation. First, participation in vocational rehabilitation does not count as return to work for the purposes of the bonus payment. Second, six of the largest TCMs are subsidiaries of companies that also own rehabilitation providers. ${ }^{33}$ By enrolling injured workers in vocational rehabilitation, the TCM can maximize the bonus payment and the rehabilitation company receives business from the state. The benefits paid to injured workers and program costs are borne by the state instead of employers. Claimants may be eligible for vocational rehabilitation as soon as the injury occurs but the median recipient enrolls in such programs after an average of ten months. Since programs last for an average of eight months, it is indeed workers near 15 months who receive vocational rehabilitation, with the programs lasting long enough to keep claimants out of work past 15 months. ${ }^{34}$

Vocational rehabilitation must begin before the worker has missed 15 months of work for the rehabilitation program to be an effective mechanism for TCMs to strategically increase claim duration in response to the incentive payment. Therefore, I estimate a linear probability model similar to equation (2), where now the dependent variable, VOCLT15, equals one if the injured worker receives vocational rehabilitation and the program begins before the worker misses 15 months of work. If there is a general increase in the use of vocational rehabilitation, the coefficient estimates on POST1 and POST2 will be positive. If the TCMs use vocational rehabilitation to strategically increase claim duration, then the coefficient estimate on POST2*INCENT will be positive and statistically significant, and the coefficient estimates on the other policy variables will be zero. Results from this regression are shown in Panel B of Table 5. The estimated coefficients on POST1 and POST2 are always small in magnitude and never statistically significant. Column (2) contains results for the sample of all common injuries. The coefficient on POST1*INCENT is small (.003) and not statistically significant, and the

\footnotetext{
programs if the individual is eligible for cash benefits while receiving the training and the individual was employed the year before vocational rehabilitation was offered. Although the social support systems of Ohio and Norway differ dramatically, if the relationship between cash benefits, program timing, and participation in vocational rehabilitation is similar for Ohio injured workers, these results suggest case managers will be able to successfully enroll injured workers in lengthy rehabilitation programs.

${ }^{33}$ Before the privatization of WC, these services were provided by the state. Private WC vocational rehabilitation providers were formed after the implementation of TCMs. Paynter, Bob. October 26, 2006. "Big money to be made in referrals for rehab; Rehab, Managed-care system for Workers' Comp hurt the workers, critics say." Cleveland Plain Dealer, A1. It would be an interesting question to compare responses of TCMs with and without an affiliated rehabilitation provider. However, data limitations prohibit this analysis. Although I can identify with certainty several TCMs that are affiliated with a vocational rehabilitation provider, I cannot identify with certainty those TCMs that do not have a vocational rehabilitation affiliate.

${ }^{34}$ Workers suffering soft tissue injuries or back injuries are those most likely to receive vocational rehabilitation.
} 
coefficient on POST2*INCENT is ten times as large (.028) and statistically significant. Once the TCM and the bonus were in place, workers with incentivized injuries became 2.8 percentage points more likely to receive vocational rehabilitation, an increase of nearly 60 percent. This is consistent with the hypothesis that case managers use enrollment in vocational rehabilitation programs to increase days away from work for particularly severe claims. Results from the other samples (excluding lacerations) are qualitatively similar and point to between a 40 and 86 percent increase in the probability an injured worker receives vocational rehabilitation benefits. These findings lend support for one mechanism case managers may use to extend claim duration, corroborating the estimated increase in duration for claims having severe incentivized injuries.

I interpret the results in Panel B as evidence case managers use enrollment in vocational rehabilitation to increase duration for claims so that they last longer than 15 months. One concern with this interpretation is that claims having incentivized injuries may be more attractive candidates for vocational rehabilitation, and the coefficient on POST2 *INCENT merely captures the increased use of vocational rehabilitation over time. I can rule out this explanation by examining whether claims having incentivized injuries have higher rates of participation when vocational rehabilitation begins after 15 months have passed. Claims lasting longer than 15 months are automatically excluded from the bonus calculation, so the case managers have no incentive to further increase duration for these claimants. ${ }^{35}$ I formally test this hypothesis by reestimating equation (2) using the dependent variable VOCGT15, which equals one if the individual receives vocational rehabilitation benefits beginning after the worker misses at least 15 months. I present the coefficient estimates in Panel C; few coefficients are statistically significant, and no clear pattern emerges. Therefore, in response to the bonus payment, TCMs appear to be strategically increasing duration for claims having incentivized injuries so that the claimant misses more than 15 months of work and the claim is excluded from the calculation of average days away from work. Furthermore, I identify one tool which TCMs use to increase duration; enrolling workers in lengthy vocational rehabilitation programs. ${ }^{36}$

\section{Discussion}

\footnotetext{
${ }^{35}$ Of course, TCMs may be able to increase duration with the promise of vocational rehabilitation beginning after 15 months. In results not shown, I confirm that the main qualitative result holds when the dependent variable is any vocational rehabilitation receipt, whether or not it was received before or after 15 months.

${ }^{36}$ Some claims will remain away from work longer than 15 months in the absence of any intervention. The TCM might enroll these workers in vocational rehabilitation to ensure they miss more than 15 months of work, or the TCM may simply ignore them. In results not shown, I find evidence consistent with case managers ignoring some claims that would exceed 15 months in the absence of any intervention.
} 


\subsection{Financial Impact of the Policy Changes}

The state contracted out case management to reduce WC claim duration and, correspondingly, WC benefits paid and employer costs. Although the following calculations are only approximations, they provide a sense of the magnitude of the costs of these policy changes to the state. First, I find that even without the bonus payment, the TCMs reduced claim duration for minor claims by an average of one-third of a day of work (see Table 4). Getting medical only claimants back to work one-third of a day sooner yields no change to total cash benefits paid. It remains an empirical question whether outcomes are harmed by returning to work sooner.

The bonus payment increased duration for cash benefit claimants diagnosed with incentivized injuries by an average of 18 days (see Table 4) and had no impact on any other group of claims. Nearly 7,000 cash benefit claimants had incentivized injuries in 2002. This corresponds to an increase of approximately 126,000 days away from work. Cash payment to workers averaged $\$ 59$ per day, so the cost of cash benefits for these additional days away from work was approximately $\$ 7.4$ million. Estimated costs to the state are even larger when I also consider the mechanism TCMs use to increase duration, enrollment in vocational rehabilitation. I estimate that approximately 250 individuals received rehabilitation because of the bonus payment, and the average cost of the program was close to $\$ 5,000$ per participant. ${ }^{37}$ This corresponds to $\$ 1.3$ million in additional costs for vocational rehabilitation. Thus, when I include the costs of vocational rehabilitation, I estimate the bonus payment may cost the state over $\$ 8.5$ million per year in additional benefits paid. It remains an empirical question whether work outcomes improve for these injured workers after additional time to heal at home and re-training through the vocational rehabilitation program. However, it is clear from these estimates that the policy changes did not succeed in reducing benefits paid to workers.

\subsection{Conclusion}

I examine the impact of a bonus payment intended to reduce claim duration among Ohio WC recipients and find evidence of costly unintended consequences. In the late 1990s, Ohio contracted out WC case management services to TCMs and incorporated a bonus payment intended to reward TCMs for expediting return-to-work. The structure of the bonus payment is

\footnotetext{
${ }^{37}$ For state VR providers, successful employment outcomes cost an average of $\$ 4,808$ per year, per participant, in FY 07. http://rsamis.ed.gov. Viewed October 21, 2008. In 2005, Minnesota WC recipients on VR incurred average costs of \$6,500 and average duration of 12.6 months. Minnesota Workers' Compensation System Report, 2005. http://www.doli.state.mn.us/pdf/wcfact05.pdf. Viewed December 10, 2008.
} 
consistent with heterogeneous effects expected along the timeline of a claim: no impact for claims before the TCM learns of the injury, efforts to reduce days away from work as soon as the TCM learns of the claim, and an increase in days away from work for claims near 15 months.

Once a claim exceeds 15 months it is excluded from the bonus payment. My results show that the bonus impacts days away from work, and the changes largely correspond to these predictions. I find no evidence that TCMs reduce duration for moderately severe claims, and the strongest evidence suggests the bonus payment induces TCMs to increase days away from work for claims having incentivized injuries. Although this is not consistent with the state's intentions, back of the envelope calculations suggest the financial impact to increasing duration for the most severe claims is so large that TCMs may not need to focus on the less severe claims to maximize their bonus. I show that the TCMs may use enrollment in vocational rehabilitation programs to extend the length of some claims, and the net effect is an increase in overall days away from work. I estimate these additional days away from work may cost the state over $\$ 8.5$ million in additional cash benefits and vocational rehabilitation.

To reduce or remove the incentive to increase duration, the state may choose to restructure the bonus payment. For example, the state could compute the bonus payment based on the first 15 months a worker is off the job. This would satisfy the goal of not penalizing TCMs with exceptionally bad draws of claims that extend longer than 15 months but would remove the incentive to keep injured workers out of work beyond 15 months.

As more contracts for privatized public services incorporate performance-based incentives, understanding effective contracts becomes even more important. I provide the first estimates examining incentives to reduce the duration of benefit receipt, and the conclusions of this paper are consistent with much of the previous empirical literature studying government contracts (e.g., Courty and Marschke, 2008; Duggan, 2004; Heckman et al., 2002). As in these other studies, I find contractors respond to the incentives in the contract, sometimes in ways inconsistent with program goals. More generally, this result should caution policymakers to carefully anticipate strategic behavior when crafting performance-based incentives. 
Figure 1: Timeline of Policy Changes: Introduction of Ohio Third-Party Case

Managers (TCMs) and Implementation of the Return-to-Work Bonus Payment

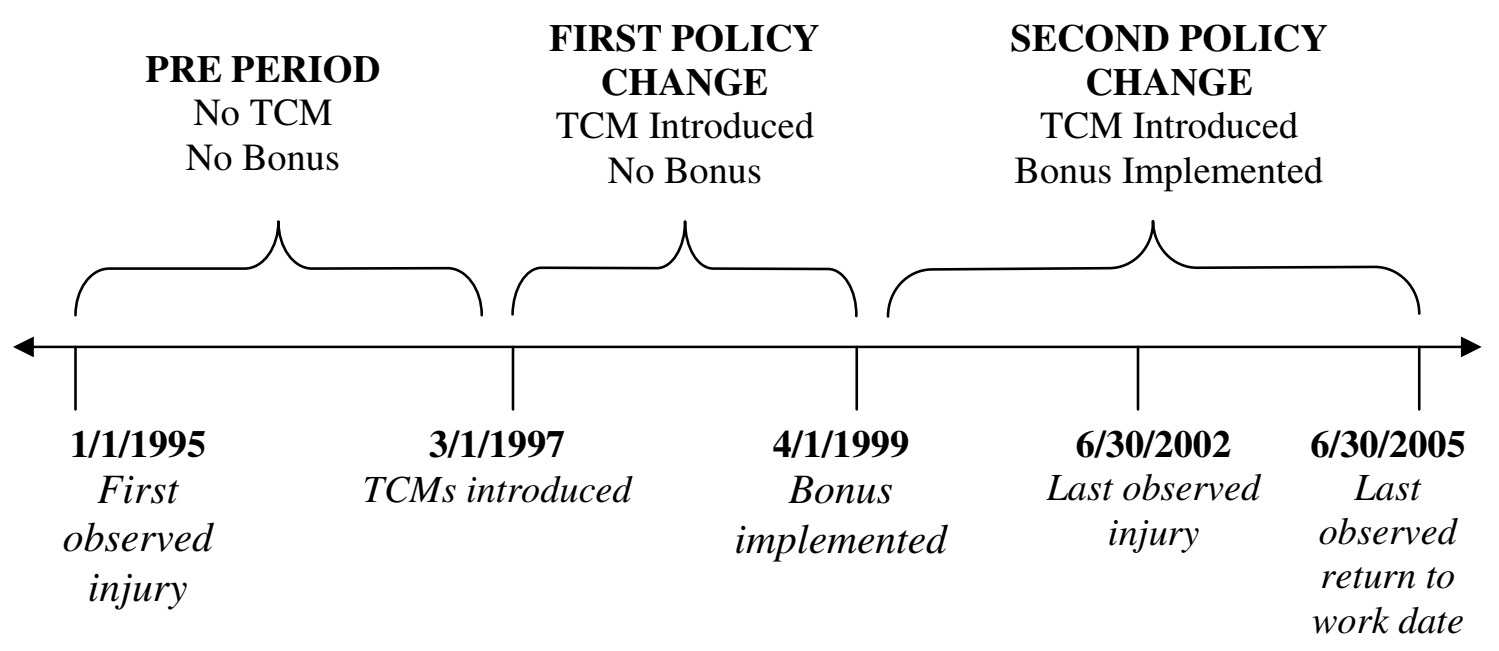

Figure 2: Share of Third-Party Case Managers (TCMs) Awarded Bonus Payment, by Quarter

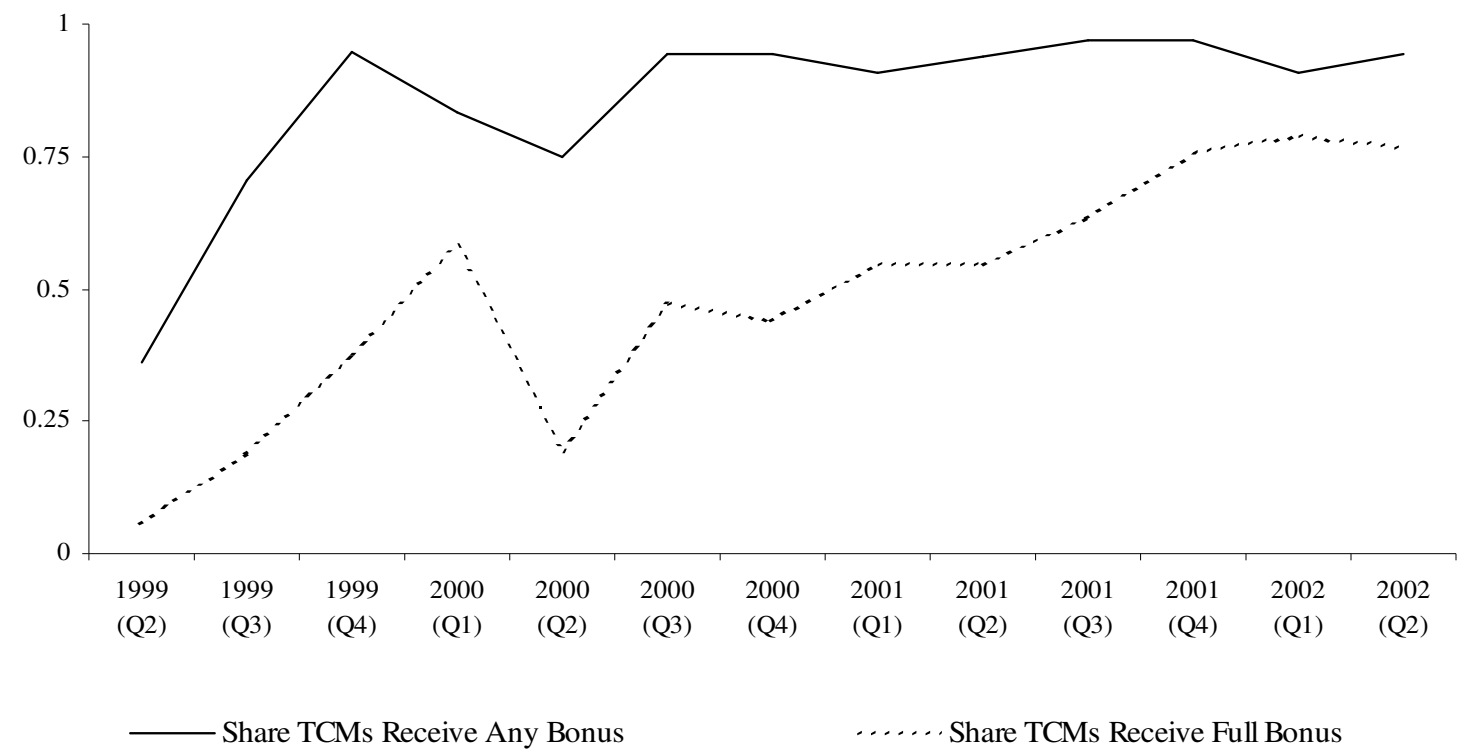


Figures 3a to 3c: Quantiles in the Distribution of Claim Duration Over Time for the Sample of All Claims (Medical Only and Cash Benefit)

Figure 3a: $90^{\text {th }}$ Percentile
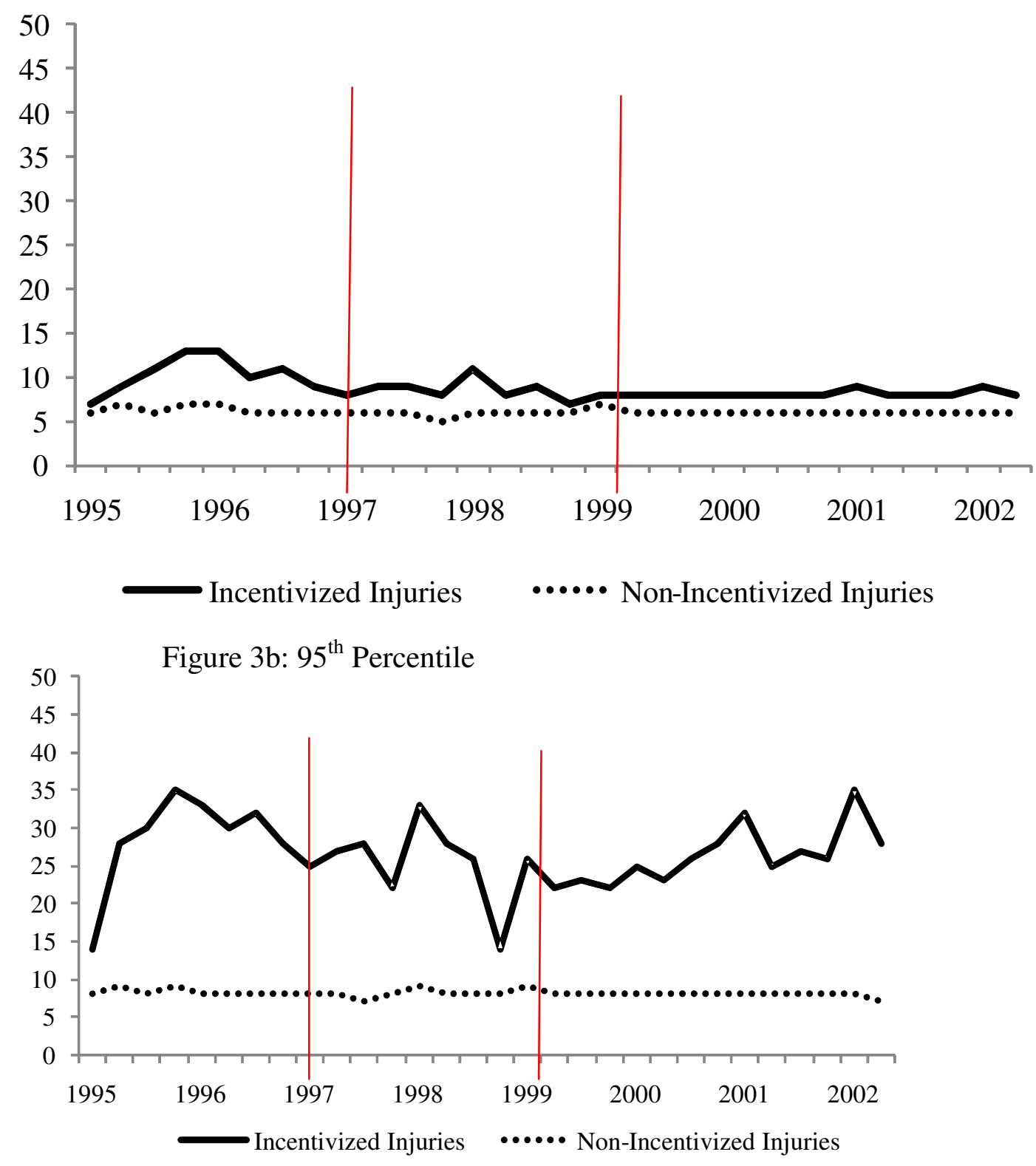


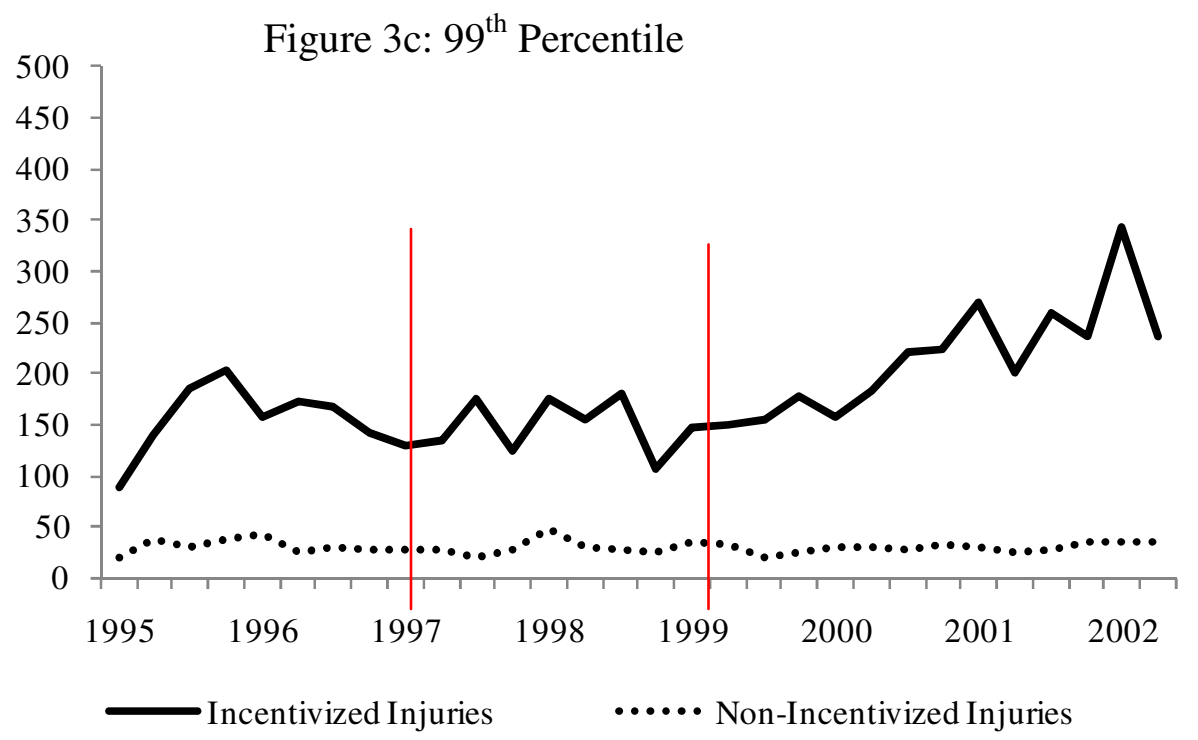

The first vertical line corresponds to the implementation of the Third Party Case Managers (TCMs) (POST1) and the second vertical line corresponds to the introduction of the bonus payment (POST2). The distributions are weighted by the inverse of the probability a claim has valid return to work information. 
Figure 4: Share of Claimants Receiving Vocational Rehabilitation Benefits Over Time

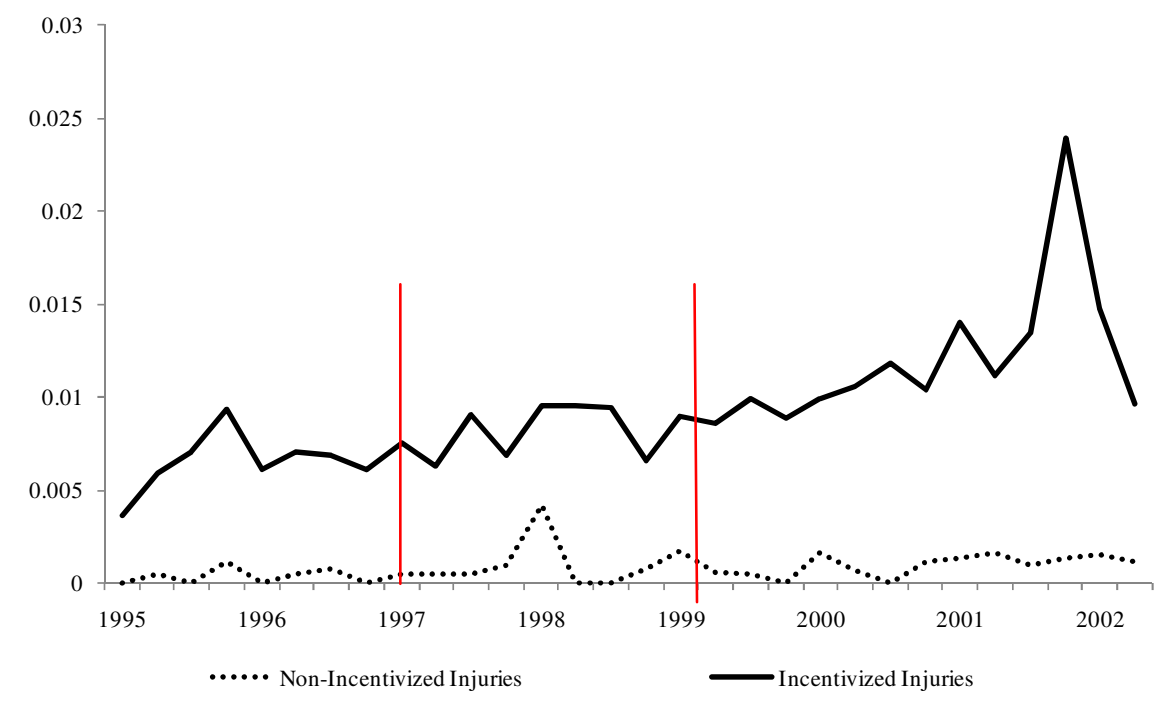

The first vertical line corresponds to the implementation of the Third-Party Case Managers (POST1) and the second vertical line marks the introduction of the bonus payment (POST2). 
Figure 5a: Coefficient Estimates and 90-Percent Confidence Intervals for POST1*INCENT from Quantile Regressions on Days Away from Work

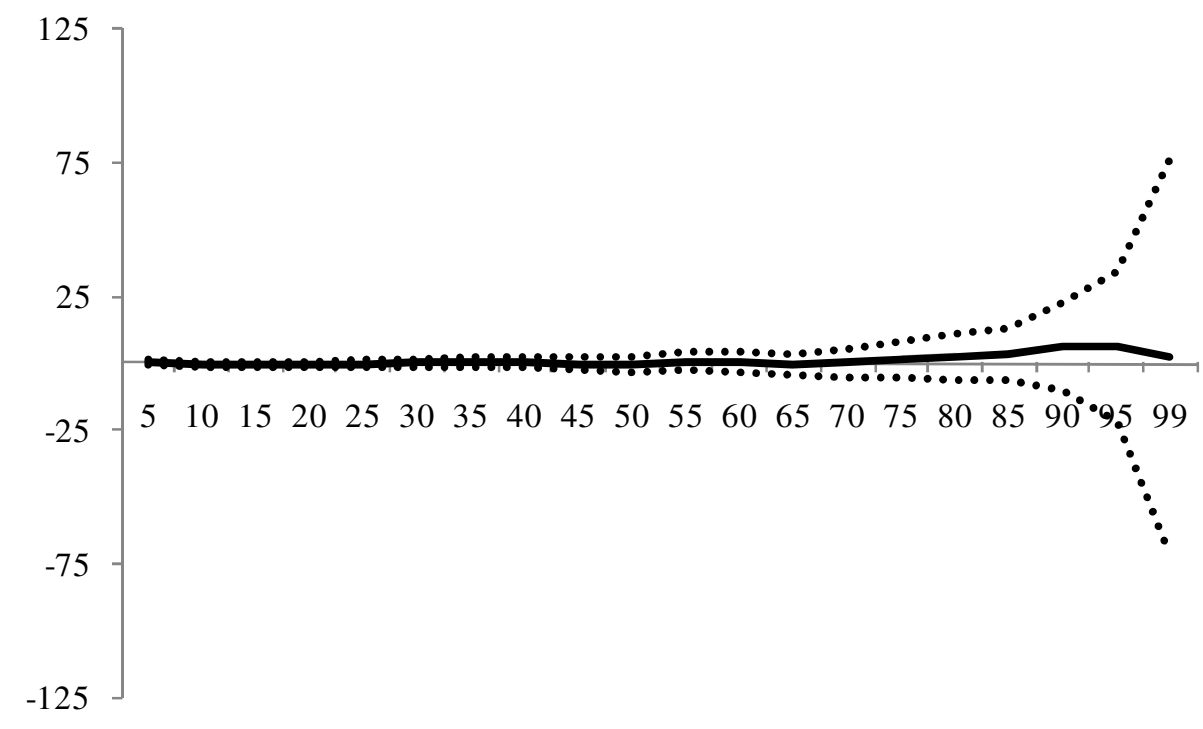

Figure 5b: Coefficient Estimates and 90-Percent Confidence Intervals for POST2*INCENT from Quantile Regressions on Days Away from Work

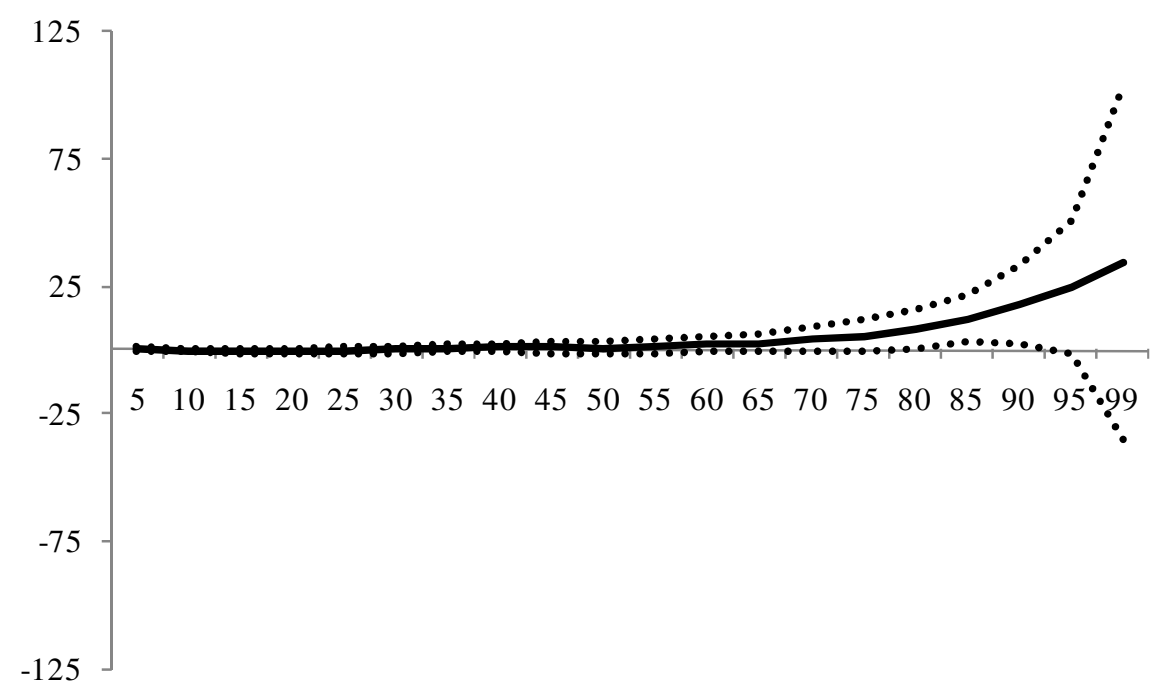

Note: The solid middle line represents the coefficients obtained by quantile regression for the variables POSTI*INCENT and POST2*INCENT. The outer lines bound the 90-percent confidence interval for these coefficients. Each regression also includes indicators for POST1, POST2, injury fixed effects, demographic characteristics, employer characteristics, 1-digit industry, 1-digit occupation, Third-Party Case Manager (TCM), as well as month and year effects. These results are for the sample of cash benefit claims. 
Table 1: Share of Claims with Most Common Injuries Over Time (5-digit ICD-9 code in parentheses)

\begin{tabular}{|c|c|c|c|c|c|c|c|}
\hline & \multicolumn{3}{|c|}{ Non-Incentivized Injuries } & & \multicolumn{3}{|c|}{ Incentivized Injuries } \\
\hline & PRE & POST1 & POST2 & & PRE & POST1 & POST2 \\
\hline Open wound, elbow/ forearm (881.00) & .133 & .128 & .131 & Open wound of finger (883.00) & .196 & $.191^{\dagger}$ & .189 \\
\hline Sprain back, thoracic $(847.10)$ & .123 & $.139^{\dagger}$ & .146 & Sprain back, lumbar (847.20) & .076 & $.082^{\dagger}$ & .081 \\
\hline Open wound of scalp (873.00) & .077 & $.063^{\dagger}$ & $.073^{\dagger}$ & Open wound of hand (882.00) & .052 & .053 & $.051^{\dagger}$ \\
\hline Open wound of scalp (922.10) & .077 & .073 & .072 & Sprain and strain of lower back (846.00) & .046 & .044 & .044 \\
\hline Open wound of forehead (873.42) & .064 & $.054^{\dagger}$ & .057 & Superficial injury of cornea (918.10) & .038 & $.028^{\dagger}$ & $.035^{\dagger}$ \\
\hline Toxic effect of venom (989.50) & .062 & $.047^{\dagger}$ & .050 & Sprain and strain of ankle (845.00) & .035 & .036 & $.042^{\dagger}$ \\
\hline Contusion, knee/lower leg (924.10) & .054 & .055 & .058 & Foreign body in eye, cornea (930.00) & .033 & $.031^{\dagger}$ & $.024^{\dagger}$ \\
\hline Other sprain/strain (848.80) & .039 & $.046^{\dagger}$ & .046 & Sprain and strain of neck (847) & .031 & $.029^{\dagger}$ & $.031^{\dagger}$ \\
\hline Toxic effect of gas/vapor (987.90) & .034 & .036 & $.026^{\dagger}$ & Contusion, finger (923.30) & .028 & $.030^{\dagger}$ & $.027^{\dagger}$ \\
\hline Open wound of hip/thigh (890.00) & .033 & .028 & .030 & Contusion, wrist and hand (923.20) & .027 & .028 & .028 \\
\hline Sprain and strain, pelvis (848.50) & .030 & $.037^{\dagger}$ & .033 & Sprain, shoulder/upper arm (840.9) & .026 & $.030^{\dagger}$ & .031 \\
\hline Conjunctivitis (372.30) & .025 & .021 & .022 & Sprain and strain of wrist (842) & .026 & .028 & .029 \\
\hline Broken tooth $(873.63)$ & .024 & .026 & $.017^{\dagger}$ & Contusion, face, scalp, neck (920.00) & .026 & .026 & $.028^{\dagger}$ \\
\hline Dermatitis (692.90) & .024 & $.029^{\dagger}$ & .029 & Contusion, knee (924.11) & .024 & .024 & .025 \\
\hline Superficial keratitis (370.24) & .021 & $.026^{\dagger}$ & .025 & Sprain and strain, knee/leg (844.9) & .023 & $.025^{\dagger}$ & $.029^{\dagger}$ \\
\hline Contusion, hip and thigh (924.00) & .019 & .018 & .018 & Contusion, foot (924.20) & .021 & .021 & $.019^{\dagger}$ \\
\hline Burn, eye (940.90) & .019 & .022 & $.015^{\dagger}$ & Foreign body in eye, other $(930.90)$ & .020 & $.027^{\dagger}$ & $.019^{\dagger}$ \\
\hline Sprain and strain, ribs (848.30) & .017 & .017 & .015 & Open wound: knee, leg, thigh (891.00) & .016 & .015 & $.016^{\dagger}$ \\
\hline Electrocution (994.80) & .016 & .013 & $.016^{\dagger}$ & Sprain and strain, hand (842.10) & .013 & .014 & $.013^{\dagger}$ \\
\hline Superficial injury of face (910) & .015 & .013 & .014 & Contusion, elbow (923.11) & .011 & .011 & .011 \\
\hline Other & .095 & $.107^{\dagger}$ & .108 & Other & .233 & $.225^{\dagger}$ & .227 \\
\hline
\end{tabular}

All means are weighted by the inverse probability a claim has missing return to work information.

${ }^{\dagger}$ Indicates mean statistically significantly different than corresponding mean in previous period (at the ten percent level). 
Table 2: Sample Composition

\begin{tabular}{|c|c|c|c|}
\hline & Full Sample & Medical Only & Cash Benefit \\
\hline Number of claims & $1,609,252$ & $1,309,466$ & 299,786 \\
\hline First claim for each injured worker ${ }^{a}$ & $1,092,981$ & 885,838 & 207,143 \\
\hline Claim has valid diagnosis information & $1,089,794$ & 885,090 & 204,704 \\
\hline $\begin{array}{l}\text { Claim was not awarded death benefit within three years of } \\
\text { injury }\end{array}$ & $1,089,733$ & 885,090 & 204,643 \\
\hline $\begin{array}{l}\text { Claim is not missing demographic, job, employer, or TCM } \\
\text { information }\end{array}$ & 963,675 & 776,003 & 187,672 \\
\hline $\begin{array}{l}\text { Claimant did not receive permanent disability benefits or a } \\
\text { lump sum benefit within three years of injury }\end{array}$ & 876,149 & 774,556 & 101,593 \\
\hline Claimant between ages 18 and 64 & 848,395 & 749,953 & 98,442 \\
\hline Claim has valid return-to-work information ${ }^{\mathrm{b}}$ & 536,783 & 480,201 & 56,582 \\
\hline Diagnosis has claims with information each period ${ }^{c}$ & 515,288 & 460,907 & 54,381 \\
\hline Diagnosis has at least 100 claims in each period & 475,974 & 431,686 & 44,288 \\
\hline Common injury sample & 127,790 & 116,064 & 11,726 \\
\hline Back injury sample & 75,505 & 61,860 & 13,645 \\
\hline Sample of cuts, excluding head injuries and complications & 120,601 & 118,189 & 2,412 \\
\hline Sample of bruises/contusions & 87,141 & 83,528 & 3,613 \\
\hline
\end{tabular}

\footnotetext{
${ }^{\mathrm{a}}$ Workers are identified by employer, date of birth, and gender

${ }^{\mathrm{b}}$ To have valid return to work information, cash benefit recipients must have checks itemized with one of three types of benefits (Temporary Total Disability benefit receipt, Living Maintenance (paid while worker is in Vocational Rehabilitation) or Non-Working Wage Loss) and the benefits must be paid within the same quarter the worker was injured or within one week of injury (if they begin in a subsequent quarter). Medical only recipients must (1) have a valid return to work date and (2) this return to work date must fall within eight days of the injury.

${ }^{c}$ If diagnosis has both medical only and cash benefit claims, both types of claims must be represented in each period to meet this criterion
} 
Table 3: Characterizing Claim Duration, Demographic, and Job Characteristics

\begin{tabular}{|c|c|c|c|c|c|c|c|}
\hline \multirow[b]{3}{*}{ Full Sample } & \multicolumn{3}{|c|}{ Non-Incentivized Injuries } & \multicolumn{3}{|c|}{ Incentivized Injuries } & \multirow{3}{*}{$\frac{\mathrm{PRE}_{\text {non }}=\mathrm{PRE}_{\mathrm{inc}}}{\mathrm{t}-\mathrm{statistic}}$} \\
\hline & $\underline{\mathrm{PRE}}$ & $\underline{\text { POST1 }}$ & POST2 & $\underline{\mathrm{PRE}}$ & POST1 & $\underline{\text { POST2 }}$ & \\
\hline & & & & & & & \\
\hline $\begin{array}{l}\text { Mean Days Away from } \\
\text { Work }\end{array}$ & $\begin{array}{c}3.854 \\
(15.149)\end{array}$ & $\begin{array}{c}3.584 \\
(17.420)\end{array}$ & $\begin{array}{c}3.561 \\
(16.971)\end{array}$ & $\begin{array}{c}10.666 \\
(58.875)\end{array}$ & $\begin{array}{c}9.807^{\dagger} \\
(58.826)\end{array}$ & $\begin{array}{c}11.675^{\dagger} \\
(70.798)\end{array}$ & -13.71 \\
\hline
\end{tabular}

Distribution of Days Away from Work (Percentiles)

$1^{\text {st }}$
$5^{\text {th }}$
$25^{\text {th }}$
$50^{\text {th }}$
$75^{\text {th }}$
$95^{\text {th }}$
$99^{\text {th }}$

Share of claims $>15$ months

Share Receive Voc. Rehab.

Demographic characteristics

Male

Married

Age

Occupation

Manager

Service worker

Support

Production

Laborer

N

$\begin{array}{cc}1 & 1 \\ 1 & 1 \\ 1 & 1 \\ 2 & 2 \\ 4 & 3 \\ 8 & 8 \\ 29 & 27 \\ .00028 & .00030 \\ .0004 & .0008\end{array}$

.760
.494

33.136

(10.742)

.757
$.440^{\dagger}$

33.167

(10.900)

.424

$.424^{\dagger}$
$33.436^{\dagger}$

(11.099)

$$
.050^{\dagger}
$$

$.050^{\dagger}$
$.238^{\dagger}$

$.064^{\dagger}$

.064
.399

.406

.216

.217

14,162

10,822

1
1
1
2
5
29
155
.0044
.0067

1
1
1
2
4
25
141
.0044
$.0081^{\dagger}$

1
1
1
2
4
26
206
$.0061^{\dagger}$
$.0111^{\dagger}$

$-7.33$

$-9.10$

$\begin{array}{cccc}.704 & .689^{\dagger} & .672^{\dagger} & 13.87 \\ .499 & .446^{\dagger} & .428^{\dagger} & -1.06 \\ 33.270 & 33.175^{\dagger} & 33.657^{\dagger} & -1.39 \\ (10.752) & (10.827) & (11.182) & \end{array}$

$$
.039
$$

.060

.391

.198

$\begin{array}{lll}.051^{\dagger} & .038^{\dagger} & 1.08 \\ .286^{\dagger} & .316^{\dagger} & -10.38 \\ .069^{\dagger} & .069 & -.78 \\ .372^{\dagger} & .340^{\dagger} & 3.46 \\ .200 & .214^{\dagger} & 5.16\end{array}$

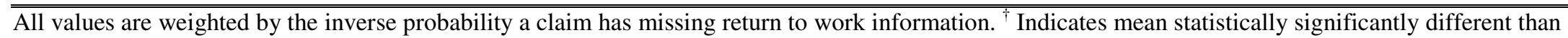
corresponding mean in previous period (at the ten percent level). 
Table 4: Characterizing Claim Duration, Results from Ordinary Least Squares

\begin{tabular}{|c|c|c|c|c|c|}
\hline Sample: & $\begin{array}{c}\text { (1) } \\
\text { All Injuries }\end{array}$ & $\begin{array}{c}(2) \\
\text { Common Injury } \\
\text { Sample }\end{array}$ & $\begin{array}{c}\text { (3) } \\
\text { Back Sprains }\end{array}$ & $\begin{array}{c}\text { (4) } \\
\text { Bruises } \\
\text { (Contusions) }\end{array}$ & $\begin{array}{l}\text { (5) } \\
\text { Cuts }\end{array}$ \\
\hline \multicolumn{6}{|c|}{ Panel A: All Claims (Medical Only and Cash Benefit) } \\
\hline POST1 & $\begin{array}{r}-1.042 \\
(.669)\end{array}$ & $\begin{array}{l}-1.833 \\
(1.258)\end{array}$ & $\begin{array}{l}-4.051^{*} \\
(2.264)\end{array}$ & $\begin{array}{l}-.895 \\
(.649)\end{array}$ & $\begin{array}{l}.056 \\
(.238)\end{array}$ \\
\hline POST1*INCENT & $\begin{array}{l}-.424 \\
(.570)\end{array}$ & $\begin{array}{l}-1.466 \\
(1.387)\end{array}$ & $\begin{array}{c}-2.376^{* *} \\
(1.095)\end{array}$ & $\begin{array}{l}.114 \\
(.393)\end{array}$ & $\begin{array}{c}-.182 * * \\
(.074)\end{array}$ \\
\hline POST2 & $\begin{array}{c}-1.676^{*} \\
(.896)\end{array}$ & $\begin{array}{l}-1.478 \\
(1.818)\end{array}$ & $\begin{array}{l}-3.877 \\
(3.738)\end{array}$ & $\begin{array}{l}-1.437 * \\
(.746)\end{array}$ & $\begin{array}{l}-.028 \\
(.311)\end{array}$ \\
\hline POST2*INCENT & $\begin{array}{l}.693 \\
(.551)\end{array}$ & $\begin{array}{l}.162 \\
(.496)\end{array}$ & $\begin{array}{l}.898^{*} \\
(.539)\end{array}$ & $\begin{array}{l}.527 * * \\
(.187)\end{array}$ & $\begin{array}{l}-.163 \\
(.038)\end{array}$ \\
\hline $\mathrm{N}$ & 475,974 & 127,790 & 75,505 & 87,141 & 120,601 \\
\hline $\mathrm{R}^{2}$ & .222 & .022 & .013 & .006 & .005 \\
\hline Mean of Dep. & 9.965 & 8.482 & 16.017 & 4.137 & 2.453 \\
\hline Var. & $(60.282)$ & $(48.364)$ & $(74.249)$ & $(21.206)$ & $(7.942)$ \\
\hline p-value & .020 & .104 & .006 & .186 & .809 \\
\hline \multicolumn{6}{|c|}{ Panel B: Medical Only Claims } \\
\hline POST1 & $\begin{array}{c}-.325^{* *} \\
(.037)\end{array}$ & $\begin{array}{c}-.281 * * \\
(.078)\end{array}$ & $\begin{array}{l}-.462 * * \\
(.039)\end{array}$ & $\begin{array}{l}-.296 * * \\
(.108)\end{array}$ & $\begin{array}{c}-.229 * * \\
(.028)\end{array}$ \\
\hline POST1*INCENT & $\begin{array}{l}-.035 \\
(.043)\end{array}$ & $\begin{array}{l}-.131 \\
(.086)\end{array}$ & $\begin{array}{l}-.017 \\
(.067)\end{array}$ & $\begin{array}{l}-.130 \\
(.082)\end{array}$ & $\begin{array}{c}-.041^{* *} \\
(.016)\end{array}$ \\
\hline POST2 & $\begin{array}{c}-.286 * * \\
(.037)\end{array}$ & $\begin{array}{c}-.255^{* *} \\
(.076)\end{array}$ & $\begin{array}{c}-.282 * * \\
(.028)\end{array}$ & $\begin{array}{c}-.366 * * \\
(.071)\end{array}$ & $\begin{array}{c}-.236^{* *} \\
(.042)\end{array}$ \\
\hline POST2*INCENT & $\begin{array}{l}-.010 \\
(.038)\end{array}$ & $\begin{array}{l}-.069 \\
(.065)\end{array}$ & $\begin{array}{l}-.011 \\
(.031)\end{array}$ & $\begin{array}{l}-.011 \\
(.049)\end{array}$ & $\begin{array}{c}-.019^{* *} \\
(.005)\end{array}$ \\
\hline $\mathrm{N}$ & 431,686 & 116,064 & 61,860 & 83,528 & 118,189 \\
\hline $\mathrm{R}^{2}$ & .090 & .075 & .022 & .037 & .019 \\
\hline Mean of Dep. & 2.525 & 2.815 & 3.353 & 2.542 & 1.953 \\
\hline Var. & $(1.861)$ & (1.994) & (2.239) & $(1.805)$ & $(1.411)$ \\
\hline p-value & .193 & .095 & .888 & .100 & .282 \\
\hline \multicolumn{6}{|c|}{ Panel C: Cash Benefit Claims } \\
\hline$\overline{\text { POST1 }}$ & $\begin{array}{l}-4.461 \\
(8.580)\end{array}$ & $\begin{array}{l}-8.960 \\
(9.244)\end{array}$ & $\begin{array}{l}-13.055 \\
(8.874)\end{array}$ & $\begin{array}{c}-7.289 \\
(11.406)\end{array}$ & $\begin{array}{c}8.652 \\
(7.024)\end{array}$ \\
\hline POST1*INCENT & $\begin{array}{l}4.450 \\
(7.204)\end{array}$ & $\begin{array}{l}-1.421 \\
(4.797)\end{array}$ & $\begin{array}{c}1.411 \\
(3.006)\end{array}$ & $\begin{array}{l}5.030 \\
(7.975)\end{array}$ & $\begin{array}{c}1.048 \\
(5.183)\end{array}$ \\
\hline POST2 & $\begin{array}{l}-11.549 \\
(10.140)\end{array}$ & $\begin{array}{c}-1.591 \\
(18.711)\end{array}$ & $\begin{array}{c}-3.287 \\
(18.623)\end{array}$ & $\begin{array}{l}-20.158 \\
(15.602)\end{array}$ & $\begin{array}{c}2.496 \\
(10.584)\end{array}$ \\
\hline POST2*INCENT & $\begin{array}{c}18.296^{* *} \\
(5.553)\end{array}$ & $\begin{array}{c}17.124 * * \\
(2.795)\end{array}$ & $\begin{array}{c}19.989 * * \\
(3.053)\end{array}$ & $\begin{array}{c}14.484 * * \\
(5.521)\end{array}$ & $\begin{array}{l}-.943 \\
(3.975)\end{array}$ \\
\hline $\mathrm{N}$ & 44,288 & 11,726 & 13,645 & 3,613 & 2,412 \\
\hline $\mathrm{R}^{2}$ & 201 & .048 & .036 & .049 & .055 \\
\hline Mean of Dep. & 90.409 & 69.756 & 78.753 & 44.487 & 29.630 \\
\hline Var. & $(189.248)$ & $(153.251)$ & $(167.537)$ & $(100.274)$ & $(51.302)$ \\
\hline $\mathrm{p}$-value & .025 & .000 & .000 & .280 & .669 \\
\hline
\end{tabular}

POST1 refers to the period when the TCMs are in place but the incentive is not (3/97-3/99) and POST2 refers to the period when the TCMs and the incentive are in place (4/99-6/02). INCENT=1 if the claim has an incentivized injury. Each regression also includes gender, age, marital status, year and month dummy variables and injury fixed effects (5-digit ICD-9 codes) as well as employer characteristics (experience rating and method of rating); 1-digit industry and occupation; and TCM effects. Standard errors are clustered by injury. P-values are reported for test of the coefficients on POST $1 *$ INCENT and POST $2 *$ INCENT being equal. Regressions are weighted by the inverse probability a claim has valid return-to-work information. *Indicates significance at the ten percent level. ** Indicates significance at the five percent level. 
Table 5: Probability a Claim Spans More Than 15 Months or Claimant Receives Vocational Rehabilitation Benefits, Linear Probability Model Results

\begin{tabular}{|c|c|c|c|c|c|}
\hline Sample: & $\begin{array}{c}1) \\
\text { All Injuries }\end{array}$ & $\begin{array}{c}(2) \\
\text { Common Injury } \\
\text { Sample }\end{array}$ & $\begin{array}{c}\text { (3) } \\
\text { Back Sprains }\end{array}$ & $\begin{array}{c}(4) \\
\text { Bruises } \\
\text { (Contusions) }\end{array}$ & $\begin{array}{l}\text { (5) } \\
\text { Cuts }\end{array}$ \\
\hline \multicolumn{6}{|c|}{ Panel A: Probability Claim Spans More than 15 Months } \\
\hline$\overline{\text { POST1 }}$ & $\begin{array}{l}-.011 \\
(.010)\end{array}$ & $\begin{array}{l}-.010 \\
(.009)\end{array}$ & $\begin{array}{l}-.011 \\
(.009)\end{array}$ & $\begin{array}{l}-.003 \\
(.014)\end{array}$ & $\begin{array}{l}.006 \\
(.008)\end{array}$ \\
\hline POST $1 *$ INCENT & $\begin{array}{l}.003 \\
(.007)\end{array}$ & $\begin{array}{l}.0007 \\
(.0035)\end{array}$ & $\begin{array}{c}-.002 * * \\
(.001)\end{array}$ & $\begin{array}{l}.006 \\
(.009)\end{array}$ & $\begin{array}{c}.002 \\
(.005)\end{array}$ \\
\hline POST2 & $\begin{array}{l}-.018 \\
(.013)\end{array}$ & $\begin{array}{l}.004 \\
(.020)\end{array}$ & $\begin{array}{l}.007 \\
(.019)\end{array}$ & $\begin{array}{l}-.020 \\
(.018)\end{array}$ & $\begin{array}{l}.004 \\
(.009)\end{array}$ \\
\hline POST2*INCENT & $\begin{array}{l}.017 * * \\
(.005)\end{array}$ & $\begin{array}{l}.016 * * \\
(.004)\end{array}$ & $\begin{array}{l}.015^{* *} \\
(.004)\end{array}$ & $\begin{array}{l}.012 * * \\
(.004)\end{array}$ & $\begin{array}{l}-.001 \\
(.003)\end{array}$ \\
\hline $\mathrm{N}$ & 44,288 & 11,726 & 13,645 & 3,613 & 2,412 \\
\hline $\mathrm{R}^{2}$ & .144 & .028 & .023 & .033 & .021 \\
\hline Mean of Dep. & .052 & .035 & .043 & .014 & .003 \\
\hline Var. & $(.223)$ & $(.185)$ & $(.202)$ & $(.116)$ & $(.056)$ \\
\hline $\mathrm{p}$-value & .050 & .001 & .010 & .478 & .550 \\
\hline \multicolumn{6}{|c|}{ Panel B: Probability Cash Benefit Recipient Receives Vocational Rehabilitation Within 15 Months of Injury } \\
\hline POST1 & $\begin{array}{l}.002 \\
(.009)\end{array}$ & $\begin{array}{l}-.004 \\
(.010)\end{array}$ & $\begin{array}{l}.010 \\
(.006)\end{array}$ & $\begin{array}{l}-.004 \\
(.017)\end{array}$ & $\begin{array}{l}-.006 \\
(.013)\end{array}$ \\
\hline POST $1 *$ INCENT & $\begin{array}{l}.012 \\
(.008)\end{array}$ & $\begin{array}{l}.003 \\
(.008)\end{array}$ & $\begin{array}{l}-.006 \\
(.006)\end{array}$ & $\begin{array}{l}.002 \\
(.005)\end{array}$ & $\begin{array}{l}.012 \\
(.009)\end{array}$ \\
\hline POST2 & $\begin{array}{l}-.013 \\
(.011)\end{array}$ & $\begin{array}{l}-.008 \\
(.012)\end{array}$ & $\begin{array}{l}-.004 \\
(.011)\end{array}$ & $\begin{array}{l}-.008 \\
(.032)\end{array}$ & $\begin{array}{l}-.009 \\
(.022)\end{array}$ \\
\hline POST2*INCENT & $\begin{array}{l}.036^{* * *} \\
(.010)\end{array}$ & $\begin{array}{l}.028 * * \\
(.005)\end{array}$ & $\begin{array}{l}.024 * * \\
(.004)\end{array}$ & $\begin{array}{l}.012^{*} \\
(.007)\end{array}$ & $\begin{array}{l}-.002 \\
(.011)\end{array}$ \\
\hline $\mathrm{N}$ & 44,288 & 11,726 & 13,645 & 3,613 & 2,412 \\
\hline $\mathrm{R}^{2}$ & .086 & .036 & .025 & .034 & .059 \\
\hline Mean of Dep. & .055 & .048 & .060 & .014 & .008 \\
\hline Var. & (.227) & $(.214)$ & $(.238)$ & $(.116)$ & $(.091)$ \\
\hline p-value & .001 & .0002 & .005 & .196 & .385 \\
\hline \multicolumn{6}{|c|}{ Panel C: Probability Cash Benefit Recipient Receives Vocational Rehabilitation More than 15 Months After Injur } \\
\hline$\overline{\text { POST1 }}$ & $\begin{array}{l}-.009 \\
(.008)\end{array}$ & $\begin{array}{l}-.011 \\
(.008)\end{array}$ & $\begin{array}{l}-.009 \\
(.006)\end{array}$ & $\begin{array}{l}-.011 \\
(.008)\end{array}$ & $\begin{array}{l}-.0002 \\
(.0031)\end{array}$ \\
\hline POST $1 *$ INCENT & $\begin{array}{l}-.0003 \\
(.0055)\end{array}$ & $\begin{array}{l}.001 \\
(.006)\end{array}$ & $\begin{array}{l}-.012 * * \\
(.006)\end{array}$ & $\begin{array}{l}-.001 \\
(.007)\end{array}$ & $\begin{array}{l}-.002 \\
(.003)\end{array}$ \\
\hline POST2 & $\begin{array}{l}-.008 \\
(.012)\end{array}$ & $\begin{array}{l}-.004 \\
(.009)\end{array}$ & $\begin{array}{l}-.014 \\
(.022)\end{array}$ & $\begin{array}{l}-.013 \\
(.009)\end{array}$ & $\begin{array}{l}-.002 \\
(.004)\end{array}$ \\
\hline POST2*INCENT & $\begin{array}{l}-.0003 \\
(.0050)\end{array}$ & $\begin{array}{l}.0005 \\
(.0050)\end{array}$ & $\begin{array}{l}-.008^{*} \\
(.004)\end{array}$ & $\begin{array}{l}.004 \\
(.006)\end{array}$ & $\begin{array}{l}-.002 \\
(.002)\end{array}$ \\
\hline $\mathrm{N}$ & 44,288 & 11,726 & 13,645 & 3,613 & 2,412 \\
\hline $\mathrm{R}^{2}$ & .118 & .023 & .015 & .031 & .025 \\
\hline Mean of Dep. & .038 & .022 & .027 & .007 & .001 \\
\hline Var. & $(.192)$ & $(.146)$ & $(.162)$ & $(.086)$ & $(.034)$ \\
\hline p-value & .991 & .660 & .393 & .269 & .751 \\
\hline
\end{tabular}

See notes to Table 4. p-values are reported for test of the coefficients on POST $1 *$ INCENT and POST $2 * I N C E N T$ being equal. Regressions are weighted by the inverse probability a claim has valid return-to-work information. *Indicates significance at the ten percent level. ** Indicates significance at the five percent level. 


\section{Works Cited}

Aakvik, A., Kjerstad, E., 2003. Skill Formation among Vocational Rehabilitation ClientsPublic Policy vs. Private Incentives. Education Economics. 11, $219-237$.

Biddle, J., 2001. Do High Claim-Denial Rates Discourage Claiming? Evidence from Workers' Compensation Insurance. The Journal of Risk and Insurance. 68, 631-658.

Biddle, J., Roberts, K., 2003. Claiming Behavior in Workers' Compensation. The Journal of Risk and Insurance. 70, 759-780.

Boden, L.I., Ruser, J.W., 2003. Workers' Compensation 'Reforms,' Choice of Medical Provider, and Reported Workforce Injuries. Review of Economics and Statistics. 85, 923-929.

Butler, R.J., Worrall, J.D., 1985. Work Injury Compensation and the Duration of Nonwork Spells. The Economic Journal. 95, 714-724.

Courty, P., Marschke, G., 2008. A General Test for Distortions in Performance Measures. Review of Economics and Statistics. 90, 428-441.

Duggan, M., 2004. Does Contracting Out Increase the Efficiency of Government Programs? Evidence from Medicaid HMOs. Journal of Public Economics. 88, 2549-2572.

Heckman, J.J., Heinrich, C., Smith, J., 2002. The Performance of Performance Standards. Journal of Human Resources. 37, 778-811.

Heinrich, C., Choi, Y., 2007. Performance-Based Contracting in Social Welfare Programs. The American Review of Public Administration. 37, 409-435.

Krueger, A.B. 1990. Workers' Compensation Insurance and the Duration of Workplace Injuries. National Bureau of Economic Research (Cambridge, MA). Working Paper No. 3253.

McInerney, M., 2008. Responses to Incentives in Public Expenditure Programs. Mimeo, University of Maryland.

Meyer, B.D., Viscusi, K.W., Durbin, D.L., 1995. Workers' Compensation and Injury Duration: Evidence from a Natural Experiment. The American Economic Review. 85, 322-340.

Neuhauser, F., Raphael, S., 2004. The Effect of an Increase in Workers' Compensation Benefits on the Duration and Frequency of Benefit Receipt. The Review of Economics and Statistics. 86, 288-302.

Neumark, D., Barth, P.S., Victor, R., 2007. The Impact of Provider Choice on Workers'

Compensation Costs and Outcomes. Industrial and Labor Relations Review. 61, 121-142.

Ohio Bureau of Workers' Compensation. n.d. Annual Report. Viewed April 21, 2007 https://www.ohiobwc.com/downloads/blankpdf/AnnualReport.pdf. 
Ohio Bureau of Workers' Compensation. 2008. MCO Report Card. Viewed December 18, 2008. https://www.ohiobwc.com/downloads/brochureware/brochures/ReportCard.pdf.

Ruser, J.W., 1998. Does Workers' Compensation Encourage Hard to Diagnose Injuries? The Journal of Risk and Insurance. 65, 101-124.

Sengupta, I., Reno, V., Burton, J.F.Jr,. 2009. Workers' Compensation: Benefits, Coverage, and Costs, 2007. National Academy of Social Insurance. (available at www.nasi.org) 


\section{Not for Publication}

\section{Appendices}

\section{Appendix A: Expected TCM Responses}

\section{A.1 Expected Impact of the Introduction of TCMS (no Bonus Payment)}

Recall that when the TCMs were first implemented, TCM compensation was strictly a function of the share of total premiums the TCM managed. Under this condition, a profit-maximizing TCM might be expected to reduce claim duration in order to remain attractive to employers. If a TCM successfully returns injured workers to their jobs, premiums for experience-rated employers will fall. However, there are two reasons employers may not have responded to TCM performance by switching to TCMs with better return-to-work outcomes.

First, Ohio employers were insulated from the full impact of their loss histories. After an extended period of rising employer costs in Ohio, the state insurer had unexpected excess reserves during the time of these policy reforms. The state chose to return this surplus to employers in the form of large premium rebates. Between July 1, 1997 and December 31, 2002, employers were eligible for premium rebates of at least 75 percent. ${ }^{38}$ Thus, even the premiums paid by the most dangerous employers were greatly reduced, overshadowing any impact the TCM may have had on premiums. Second, employers may have had a difficult time evaluating and differentiating between TCMs. Although the state publishes analyses describing TCM performance to better help employers select among TCMs, few employers have much interaction with their selected TCMs. Most employers have fewer than ten claims per year, and about 80 percent of these claims are resolved before the TCM becomes involved. For this reason, the bulk of employers may not have been compelled to switch TCMs, and maintaining employer clients was unlikely to have been an important aspect of the TCM profit function during this period. Using Ohio administrative claims data, I calculate that fewer than ten percent of employers switch TCMs each year, providing further support for this claim. Therefore, I assume that the marginal benefit to a TCM for reducing a claim's duration during this period is near zero.

Given the infrastructure changes mandated by the state, the structure of TCM compensation, and employer behavior, the impact of the TCM on claim duration is predicted to

\footnotetext{
${ }^{38}$ Personal Communication, Elizabeth Bravender, Ohio Bureau of Workers' Compensation, August 3, 2006. In 1998, employers received an even larger refund.
} 
change as a claim develops from the date of injury. To illustrate this, I make a few simplifying assumptions. First, I assume that every claim in the TCMs portfolio was injured on the same day. I also assume that when a TCM decides whether or not to attempt to reduce duration, the TCM makes the decision to act considering the entire portfolio of claims. I make this assumption because it is difficult to predict a claim's duration, especially early in the claim. Suppose case managers make calls each week, then each week the case manager assesses whether the marginal benefit of calling the entire portfolio of claims outweighs the marginal cost of these calls.

In Figure A-1, I illustrate the marginal costs and benefits associated with reducing duration. The horizontal axis measures time away from work if the TCM attempts to reduce duration, called $d^{R E D}$. There are no marginal costs or benefits associated with the first week a worker misses of work because the TCM cannot impact duration before the claim is filed. ${ }^{39}$ For claims that would return to work within one week, only infrastructure changes, such as insurance cards, can influence duration. These infrastructure changes may have streamlined the path to the first doctor's appointment and reduced duration. Therefore, duration is predicted to decrease for minor claims. For claims lasting longer than one week, the marginal cost of reducing claim duration always exceeds the marginal benefit because of the assumption that maintaining employer clients was not an important component of a TCMs profit function. Thus, before the bonus was implemented, case managers had no incentive to influence claim duration above and beyond the impact of infrastructure changes such as insurance cards.

\section{A.2 Expected Impact of the Bonus Payment on Incentivized Injuries}

After the second policy change, the introduction of the bonus payment, TCMs may respond by affecting claim duration or by influencing doctors to strategically re-label injuries as incentivized or non-incentivized. Although strategic re-labeling is present in response to other public programs (e.g., Dafny, 2005; Fisman and Wei, 2004; and Silverman and Skinner, 2004), I do not expect to find such a reaction to the bonus payment. A doctor diagnoses an injured worker before the claim is even filed with the TCM. For strategic re-labeling to be successful, TCMs would have to convince doctors to comply even though the doctors do not directly benefit from a higher bonus payment. In section A.3 of this appendix, I examine strategic re-labeling and

\footnotetext{
${ }^{39}$ I assume that providing insurance cards incurs a small, fixed cost.
} 
confirm that doctors do not appear to be manipulating claims in this way. Therefore, I focus on the incentives facing TCMs to impact days away from work.

The bonus payment is predicted to impact claim duration differentially for claims having incentivized and non-incentivized injuries. The case managers are predicted to treat claims with non-incentivized injuries in the same way before and after the bonus payment is implemented (Figure A-1). For claims having incentivized injuries, recall that the bonus is essentially a decreasing function of average days away from work for claimants that return to work in less than 15 months. Therefore, the structure of the bonus suggests that a profit-maximizing TCM will react with heterogeneous responses as a claim develops over time. These actions correspond to changes in duration that vary by a claim's underlying severity.

Figure A-2 characterizes the marginal costs and benefits associated with reducing claim duration for incentivized injuries once the bonus payment is in place. As in Figure A-1, there are no marginal costs or benefits before claims are filed in the first week after injury. Once the TCM learns of the injury, the marginal cost of reducing duration remains the same- the cost of a phone call. However, the marginal benefit now exceeds the marginal cost because the bonus payment is a function of duration for injured workers having incentivized injuries. In a given week, the marginal benefit to the TCM for claim reduction efforts is the change in the bonus payment that arises from workers returning to their jobs that week instead of when they would have returned in the absence of any intervention. The marginal benefit falls over time because the bonus is a decreasing function of average days away from work. When the TCM first learns of the claim, the marginal benefit to a TCM of reducing duration exceeds the marginal cost of these efforts. Therefore, claimants are exposed to an aggressive return-to-work campaign after one week away from work. A characteristic of many TCM data management systems suggests case managers can focus these efforts on claimants with incentivized injuries. In many TCMs, the data management system used to track claims informs the case managers whether the claim has an incentivized injury, the injury's goal days away from work, and the amount of time since the injury. ${ }^{40}$

Recall that claims that extend longer than 15 months are excluded from the bonus payment. Thus, there is a threshold beyond which it benefits TCMs to encourage claimants to

\footnotetext{
${ }^{40}$ Ohio Employee Health Partnership. http://www.systoc.com/Tracker/Summer99/DoDM.htm viewed 8/12/06 Lori Newhouse, CareWorks, personal communication, August 18, 2006.
} 
remain out of work past 15 months. A TCM might do this in two ways: actively increase a claim's duration or ignore the claimant in the hope that the worker will return to the job once 15 months have passed. ${ }^{41}$ To illustrate this point, I define two additional measures of duration for each worker. Recall $d^{R E D}$ quantifies the number of days a worker misses if the TCM attempts to reduce duration. If the TCM does not intervene at all, a claim's duration is given by $d^{O H}$, which can be thought of as the counterfactual or amount of time the injured worker would have missed if the injury had occurred when the state of Ohio managed claims. If the TCM attempts to make an injured worker remain out of work longer, the claim would miss $d^{L O N G}$ days away from work. The TCM is predicted to actively increase duration for claims with incentivized injuries having $d^{L O N G}>15$ months, the threshold beyond which TCMs benefit if the claimant remains out of work past 15 months. The case manager might use enrollment in vocational rehabilitation to increase duration for these claims. Furthermore, TCMs have a second financial incentive to enroll injured workers in vocational rehabilitation programs; the largest TCMs are subsidiaries of companies that also own vocational rehabilitation providers.

Some injured workers will miss more than 15 months of work even if the TCM does not attempt to make the claim longer ( $d^{O H}>15$ months), so the TCM does not need to actively increase duration for these claims. However, these claims are difficult to identify so it is an empirical question whether or not the TCM actively works to increase duration for all claims past the threshold beyond which TCMs benefit if the claimant remains out of work past 15 months or ignores some claims - those that will miss 15 months no matter what the TCM does. I explore this matter in the empirical section. ${ }^{42}$

\section{A.3 Investigating Strategic Re-Labeling}

A TCM might maximize the bonus payment by strategically assigning claims as incentivized or non-incentivized. In essence, the TCM may not impact duration but influence how claims are coded to maximize the bonus payment. Such re-labeling responses are fairly widespread in response to other government programs. There is an established literature finding such behavior

\footnotetext{
${ }^{41}$ The TCM has an incentive to identify these claims and not invest in reducing duration, but this is difficult to do. Therefore, the case manager may unsuccessfully attempt to get these claimants back to work early in the claim.

${ }^{42}$ The five largest TCMs and their affiliated vocational rehabilitation providers are CareWorks (VocWorks), CompManagement HealthSystems (Integrated Benefits Management), GatesMcDonald HealthPlus (unnamed affiliate referenced at www.gmcdhealthplus.com/HealthPlus/employer-services.jsp\#vocational-rehab. Viewed May 21, 2008), Sheakley Unicomp (Parman Group), and 1800OHIOCOMP (VocRehab One). Paynter, Bob. October 26, 2006. "Big money to be made in referrals for rehab; Rehab, Managed-Care system for Workers' Comp hurt the workers, critics say." Cleveland Plain Dealer, A1.
} 
to evade taxes (e.g., Fisman and Wei, 2004) and to increase hospital reimbursement after a Medicare rate reduction (e.g., Dafny, 2005; Silverman and Skinner, 2004). For a TCM to maximize the bonus payment by strategic re-labeling, the doctor would code severe injuries as non-incentivized, and TCMs ignore these injuries-no increase or decrease in duration. Results presented in Table 4 quantify an increase in days away from work for claims having incentivized injuries. However, if doctors are re-labeling some severe injuries as non-incentivized, then these estimated increases in duration are upper bounds of the policy's impact. These estimates exclude severe claimants re-labeled as non-incentivized, and duration for these injuries does not change as a result of the bonus payment.

However, I do not anticipate finding such a re-labeling effect in this case. The presence of strategic re-labeling would be more plausible if the bonus payment induces a reduction in claim duration, and for strategic re-labeling to be successful, TCMs must convince doctors to comply because the doctor diagnoses patients before the TCM learns of the claim. This may be difficult for TCMs to do because the agent who would have to do the re-coding, the physician, does not directly benefit from a higher bonus. ${ }^{43}$

The doctor makes the diagnosis at the first visit, before it is known whether a particular claim will be longer or shorter than average. At this appointment, the doctor acquires information about the expected length of a particular claim, as well as information needed to file the claim that is available in the administrative data: the injured worker's age, gender, marital status, and occupation; these attributes are predictors of claim duration. ${ }^{44}$ For example, older, female claimants have above average duration. Since the state benchmarks do not depend on these characteristics, one way for case managers to reduce average duration would be to diagnose all older, female claimants with non-incentivized injuries and vice versa.

To test if this observable information has an impact on the diagnosis made by the doctor, I regress whether or not the claim has an incentivized diagnosis on the doctor-observed demographic characteristics. I allow these characteristics to vary based on the time period when the claim was filed, as shown in the equation below

\footnotetext{
${ }^{43}$ In the previous re-labeling literature, the agents doing the re-labeling benefit from the strategic behavior (e.g., the hospital employees who map a physician's diagnosis to a Medicare Diagnosis Related Group (DRG), as is the case in Dafny (2005), or an exporter labeling a product to evade taxes, as in Fisman and Wei (2004)).

${ }^{44}$ Form BWC-1101 (Rev. 8/2004) FROI-1 "First Report of an injury, occupational disease or death" ohiobwc.com.
} 


$$
\begin{gathered}
\operatorname{INCENT~}_{i, j, t}=\alpha_{0}+\alpha_{1} \text { POST }_{t}+\alpha_{2} \text { POST }_{t}+\alpha_{3} \text { PRE }_{t} * X_{i}+\alpha_{4} \text { POST1 }_{t} * X_{i}+\alpha_{5} \text { POST }_{t} * X_{i} \\
+\kappa_{j}+\eta_{t}+\mu_{i, j, t}
\end{gathered}
$$

where $P R E^{*} X$ is a vector of demographic characteristics interacted with a dummy variable for the PRE period and $\kappa$ captures general descriptors of the injury, not the five-digit ICD-9 codes. Thus, if doctors are shifting diagnoses to manipulate the bonus payment, the coefficient on $P O S T 2 * A G E$ is expected to be negative and statistically significantly different than the coefficients on $P R E^{*} A G E$ and $P O S T 1^{*} A G E$ because before the bonus is implemented, there is no reason for doctors to strategically diagnose injuries.

The results from this analysis are shown in Appendix Table A. The results in Panel A quantify any differences in the probability claims are assigned incentivized injuries between periods. In column (1), before the sample composition is restricted, it appears claims are less likely to have incentivized injuries over time. However, once the sample is restricted to common injuries, there is no clear trend in the probability of being diagnosed with an incentivized injury. In Panel B, I present results from equation (3). Only the results from the demographic characteristics interacted with POST2 are shown, but the results from the other two periods are quite similar. Panel B, column (1) contains results from the full sample of claims. Few coefficients are statistically significantly different than zero and all are small in magnitude. The coefficient on POST2*MALE is -.012. In POST2, males are 1.2 percentage points, or 1.4 percent, less likely to be diagnosed with an incentivized injury than female workers. ${ }^{45}$ The coefficient on $P O S T 2 * A G E$ is .0006 . This suggests that an individual ten years older than an otherwise observably similar claimant is .6 percentage points, or less than one percent, more likely to be diagnosed with an incentivized injury once the bonus is implemented. These are both small effects that are inconsistent with the re-labeling hypothesis. Since older workers return to work more slowly, a negative coefficient would be consistent with TCMs re-labeling to maximize the bonus payment. In total, the results show no evidence of strategic re-labeling in any sample; the coefficients are small, rarely statistically significant, and often the sign is inconsistent with the re-labeling hypothesis.

\footnotetext{
${ }^{45}$ In fact, the only statistically significant difference in the interaction terms for a demographic characteristic over time is found for MALE*PRE and MALE*POST2 in columns (1) and (2). However, not only are both coefficients close to zero, in POST2, males are less likely to be assigned an incentivized injury. This is inconsistent with the relabeling hypothesis.
} 


\section{Appendix Works Cited}

Dafny, Leemore. 2005. "How do Hospitals respond to Price Changes?" American Economic Review, 95(5): 1525-1547.

Fisman, Raymond and Shang-Jin Wei. 2004. “Tax Rates and Tax Evasion: Evidence from 'Missing Imports' in China." Journal of Political Economy, 112(2).

Silverman, Elaine and Jonathan Skinner. 2004. "Medicare Upcoding and Hospital Ownership." Journal of Health Economics, 23(2): 369-389. 
Figure A-1: Marginal Costs and Benefits to Third-Party Case Managers (TCMs) of Reducing Claim Duration in Absence of Bonus Payment

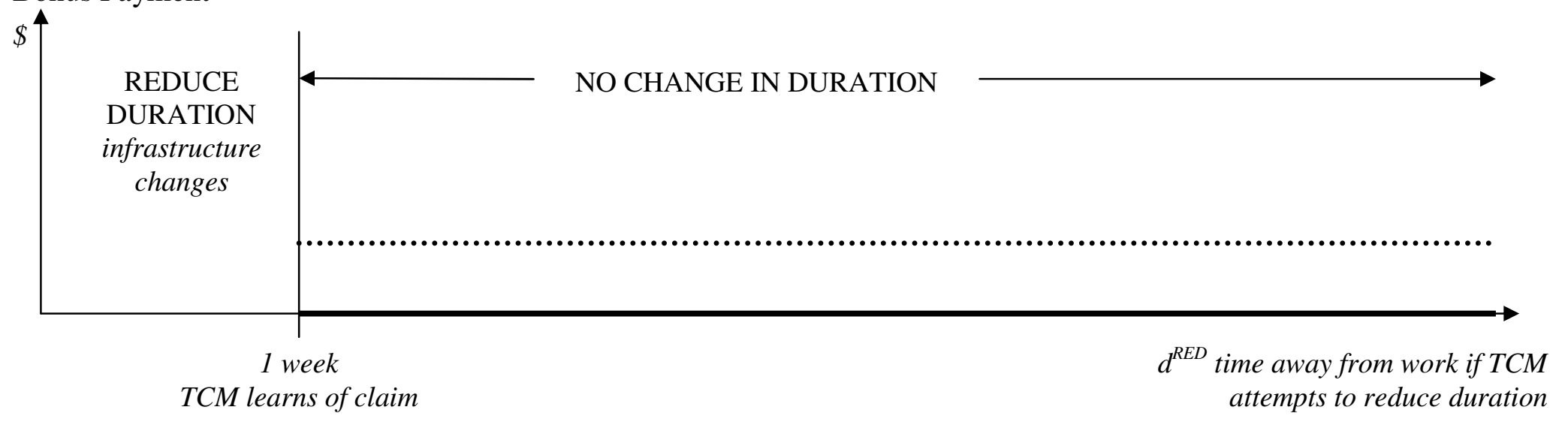

Marginal cost of calling portfolio of claims in week $t \quad \ldots . . . . .$.

Marginal change in TCM compensation of calling portfolio of claims in week $t$ 
Figure A-2: Marginal Costs and Benefits to Third-Party Case Managers (TCMs) of Reducing Claim Duration for Incentivized Injuries After Bonus Payment

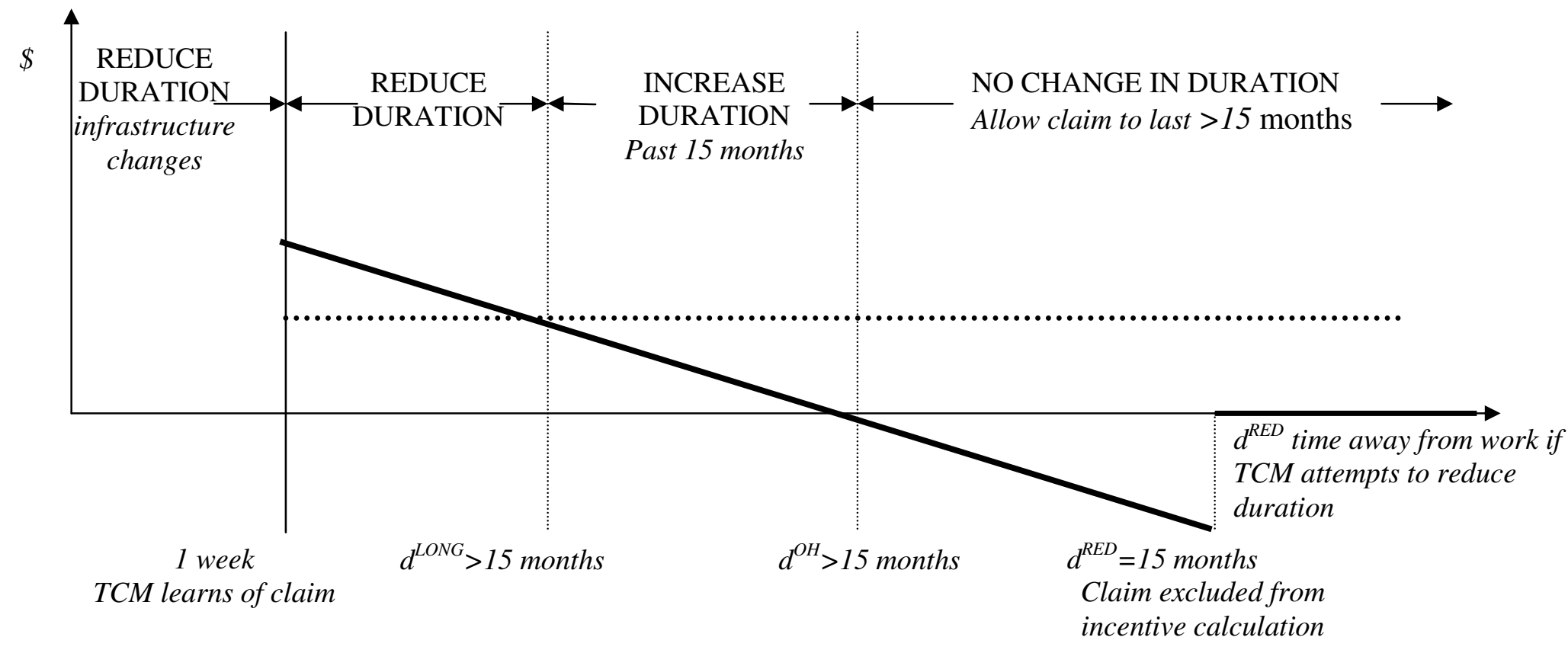

Marginal cost of calling portfolio of claims in week t

Marginal change in TCM compensation of calling portfolio of claims in week $t$ 
Appendix Table A: Probability a Claim is Assigned an Incentivized Diagnosis, Linear Probability Model

\begin{tabular}{|c|c|c|c|c|c|}
\hline & $(1)$ & $(2)$ & (3) & $(4)$ & $(5)$ \\
\hline Sample: & $\begin{array}{c}\text { All } \\
\text { Injuries }\end{array}$ & $\begin{array}{c}\text { Common } \\
\text { Injury } \\
\text { Sample }\end{array}$ & $\begin{array}{c}\text { Back } \\
\text { Sprains }\end{array}$ & $\begin{array}{c}\text { Bruises } \\
\text { (Contusions) }\end{array}$ & Cuts \\
\hline \multicolumn{6}{|l|}{ Panel A } \\
\hline POST1 & $\begin{array}{c}-.012 * * \\
(.003)\end{array}$ & $\begin{array}{l}-.002 \\
(.010)\end{array}$ & $\begin{array}{l}.006 \\
(.010)\end{array}$ & $\begin{array}{l}-.007 \\
(.007)\end{array}$ & $\begin{array}{l}-.002 \\
(.003)\end{array}$ \\
\hline POST2 & $\begin{array}{c}-.021 * * \\
(.004)\end{array}$ & $\begin{array}{l}-.018 \\
(.012)\end{array}$ & $\begin{array}{l}-.005 \\
(.012)\end{array}$ & $\begin{array}{l}-.014 \\
(.009)\end{array}$ & $\begin{array}{l}.003 \\
(.004)\end{array}$ \\
\hline $\mathrm{R}^{2}$ & .38 & .18 & .01 & .37 & .82 \\
\hline \multicolumn{6}{|l|}{ Panel B } \\
\hline POST2 & $\begin{array}{l}-.007 \\
(.009)\end{array}$ & $\begin{array}{l}.012 \\
(.024)\end{array}$ & $\begin{array}{l}.037 \\
(.027)\end{array}$ & $\begin{array}{l}.015 \\
(.019)\end{array}$ & $\begin{array}{c}-.022 * * \\
(.007)\end{array}$ \\
\hline POST2*Male & $\begin{array}{c}-.012 * * \\
(.001)\end{array}$ & $\begin{array}{c}-.028 * * \\
(.004)\end{array}$ & $\begin{array}{c}-.009 * * \\
(.004)\end{array}$ & $\begin{array}{c}-.028 * * \\
(.003)\end{array}$ & $\begin{array}{l}.004 * * \\
(.001)\end{array}$ \\
\hline POST $2 *$ Age & $\begin{array}{l}.0006^{* *} \\
(.00006)\end{array}$ & $\begin{array}{l}.0008 * * \\
(.0002)\end{array}$ & $\begin{array}{l}.002 * * \\
(.0002)\end{array}$ & $\begin{array}{l}-.001 * * \\
(.0001)\end{array}$ & $\begin{array}{l}.0001 * * \\
(.00005)\end{array}$ \\
\hline POST2*Married & $\begin{array}{l}.003 * \\
(.001)\end{array}$ & $\begin{array}{l}.003 \\
(.003)\end{array}$ & $\begin{array}{l}.001 \\
(.004)\end{array}$ & $\begin{array}{l}-.0003 \\
(.003)\end{array}$ & $\begin{array}{l}-.002 \\
(.001)\end{array}$ \\
\hline POST2*Manager & $\begin{array}{l}.011^{*} \\
(.007)\end{array}$ & $\begin{array}{l}.031^{*} \\
(.019)\end{array}$ & $\begin{array}{l}.041 * \\
(.021)\end{array}$ & $\begin{array}{l}.004 \\
(.014)\end{array}$ & $\begin{array}{l}.007 \\
(.006)\end{array}$ \\
\hline POST2*Service Worker & $\begin{array}{l}.004 \\
(.006)\end{array}$ & $\begin{array}{l}.025 \\
(.017)\end{array}$ & $\begin{array}{l}.030 \\
(.020)\end{array}$ & $\begin{array}{l}.006 \\
(.013)\end{array}$ & $\begin{array}{l}.002 \\
(.005)\end{array}$ \\
\hline POST2*Support Worker & $\begin{array}{l}-.003 \\
(.006)\end{array}$ & $\begin{array}{c}.004 \\
(.018)\end{array}$ & $\begin{array}{l}.017 \\
(.020)\end{array}$ & $\begin{array}{c}.002 \\
(.014)\end{array}$ & $\begin{array}{l}-.0001 \\
(.0060)\end{array}$ \\
\hline POST2*Production Worker & $\begin{array}{l}.005 \\
(.006)\end{array}$ & $\begin{array}{l}.010 \\
(.017)\end{array}$ & $\begin{array}{l}.016 \\
(.020)\end{array}$ & $\begin{array}{l}-.010 \\
(.013)\end{array}$ & $\begin{array}{l}.002 \\
(.005)\end{array}$ \\
\hline POST2*Laborer & $\begin{array}{l}.010 \\
(.006)\end{array}$ & $\begin{array}{l}.024 \\
(.017)\end{array}$ & $\begin{array}{l}.024 \\
(.020)\end{array}$ & $\begin{array}{l}-.007 \\
(.013)\end{array}$ & $\begin{array}{l}-.002 \\
(.005)\end{array}$ \\
\hline $\mathrm{R}^{2}$ & .38 & .19 & .01 & .37 & .82 \\
\hline $\mathrm{N}$ & 475,974 & 127,790 & 75,505 & 87,141 & 120,601 \\
\hline Mean of Dep. Variable & .88 & .78 & .89 & .89 & .92 \\
\hline \multicolumn{6}{|c|}{$\begin{array}{l}\text { Each regression includes indicators for POST1 and POST2, year and month dummy variables, broad injury } \\
\text { categories (bruised head, cut head, bruised back, eye, sprained back, bruised arm, fractured arm, cut arm, } \\
\text { sprained arm, cut hand, bruised leg, fractured leg, cut leg, sprained leg, and the left out category is other), } \\
\text { employer characteristics, 1-digit industry, and TCM fixed effects. The regressions in Panel A also include } \\
\text { demographic characteristics and 1-digit occupation. The regressions in Panel B also include a vector of } \\
\text { demographic and occupation characteristics interacted with PRE and POST1. Linear probability models } \\
\text { are weighted by the inverse probability a claim has valid return-to-work information. } \\
\text { * Indicates significance at the ten percent level } \\
\text { ** Indicates significance at the five percent level }\end{array}$} \\
\hline
\end{tabular}


Appendix B: Incidence of missing return to work information

\begin{tabular}{|c|c|c|c|}
\hline & $\begin{array}{l}\text { Full } \\
\text { Sample }\end{array}$ & $\begin{array}{l}\text { Medical } \\
\text { Only }\end{array}$ & $\begin{array}{l}\text { Cash } \\
\text { Benefit }\end{array}$ \\
\hline \multicolumn{4}{|c|}{$\begin{array}{l}\text { Panel A: Sample size before valid return-to-work information criteria } \\
\text { imposed }\end{array}$} \\
\hline PRE & 270,163 & 235,599 & 34,564 \\
\hline POST1 & 237,692 & 211,861 & 25,831 \\
\hline POST2 & 340,540 & 302,493 & 38,047 \\
\hline \multicolumn{4}{|c|}{ Incentivized Injuries } \\
\hline PRE & 224,294 & 193,807 & 30,487 \\
\hline POST1 & 198,949 & 175,994 & 22,955 \\
\hline POST2 & 286,469 & 252,294 & 34,175 \\
\hline \multicolumn{4}{|c|}{ Non-Incentivized Injuries } \\
\hline PRE & 45,869 & 41,792 & 4,077 \\
\hline POST1 & 38,743 & 35,867 & 2,876 \\
\hline POST2 & 54,071 & 50,199 & 3,872 \\
\hline
\end{tabular}

Panel B: Sample size after valid return-to-work information criteria imposed

$\begin{array}{llll}\text { PRE } & 140,418 & 116,177 & 24,241 \\ \text { POST1 } & 109,268 & 91,020 & 18,248 \\ \text { POST2 } & 300,113 & 273,004 & 27,109 \\ \text { Incentivized Injuries } & & & \\ \text { PRE } & 117,043 & 95,288 & 21,755 \\ \text { POST1 } & 92,195 & 75,807 & 16,388 \\ \text { POST2 } & 253,314 & 228,751 & 24,563 \\ \text { Non-Incentivized Injuries } & & & \\ \text { PRE } & 23,375 & 20,889 & 2,486 \\ \text { POST1 } & 17,073 & 15,213 & 1,860 \\ \text { POST2 } & 46,799 & 44,253 & 2,546 \\ \end{array}$

\section{Panel C}

Share of Incentivized Injuries missing return-to-work information

$\begin{array}{llll}\text { PRE } & .478 & .508 & .286 \\ \text { POST1 } & .537 & .569 & .286 \\ \text { POST2 } & .116 & .093 & .281\end{array}$

Share of Non-Incentivized Injuries missing return-to-work information

\begin{tabular}{llll} 
PRE & .490 & .500 & .390 \\
POST1 & .559 & .576 & .353 \\
POST2 & .134 & .118 & .343 \\
\hline
\end{tabular}

PRE refers to the period before the Third-Party Case Managers (TCMs) or incentive payment are implemented (1/95-2/97); POST1 refers to the period when the TCMs are in place but the incentive is not (3/97-3/99); and POST2 refers to the period when the TCMs and incentive are in place (4/99-6/02). There are 848,395 observations before the valid return-to-work information criteria are imposed, and 549,799 observations remain after it is imposed. 
Appendix C: Probability claim spans more than 1 week (and receives cash benefits), Linear Probability Model

\begin{tabular}{|c|c|c|c|c|c|}
\hline & (1) & (2) & (3) & (4) & (5) \\
\hline Sample: & $\begin{array}{c}\text { All } \\
\text { Injuries }\end{array}$ & $\begin{array}{c}\text { Common } \\
\text { Injury } \\
\text { Sample } \\
\end{array}$ & $\begin{array}{c}\text { Back } \\
\text { Sprains }\end{array}$ & $\begin{array}{c}\text { Bruises } \\
\text { (Contusions) }\end{array}$ & Cuts \\
\hline POST1 & $\begin{array}{c}-.009 * * \\
(.004)\end{array}$ & $\begin{array}{c}-.019 * * \\
(.007)\end{array}$ & $\begin{array}{c}-.037 * * \\
(.007)\end{array}$ & $\begin{array}{c}-.017 * * \\
(.006)\end{array}$ & $\begin{array}{l}.006 \\
(.007)\end{array}$ \\
\hline POST $1 *$ INCENT & $\begin{array}{l}-.009 * \\
(.005)\end{array}$ & $\begin{array}{l}-.013 \\
(.012)\end{array}$ & $\begin{array}{c}-.024 * * \\
(.009)\end{array}$ & $\begin{array}{l}.009^{*} \\
(.005)\end{array}$ & $\begin{array}{c}-.008 * * \\
(.004)\end{array}$ \\
\hline POST2 & $\begin{array}{l}-.013^{*} \\
(.006)\end{array}$ & $\begin{array}{c}-.030 * * \\
(.008)\end{array}$ & $\begin{array}{c}-.059 * * \\
(.005)\end{array}$ & $\begin{array}{l}-.016^{*} \\
(.007)\end{array}$ & $\begin{array}{l}.006 \\
(.007)\end{array}$ \\
\hline POST2*INCENT & $\begin{array}{l}-.011^{*} \\
(.006)\end{array}$ & $\begin{array}{l}-.015 \\
(.012)\end{array}$ & $\begin{array}{c}-.027 * * \\
(.004)\end{array}$ & $\begin{array}{c}.007 \\
(.004)\end{array}$ & $\begin{array}{c}-.006 * * \\
(.003)\end{array}$ \\
\hline Male & $\begin{array}{l}-.001 \\
(.002)\end{array}$ & $\begin{array}{l}-.002 \\
(.004)\end{array}$ & $\begin{array}{l}-.016 \\
(.004)\end{array}$ & $\begin{array}{l}.004^{*} \\
(.002)\end{array}$ & $\begin{array}{l}.002 * \\
(.001)\end{array}$ \\
\hline Age & $\begin{array}{l}.001 * * \\
(.0002)\end{array}$ & $\begin{array}{l}.001 * * \\
(.0003)\end{array}$ & $\begin{array}{l}.002 * * \\
(.0002)\end{array}$ & $\begin{array}{l}.001 * * \\
(.0001)\end{array}$ & $\begin{array}{l}.0002 * * \\
(.0001)\end{array}$ \\
\hline Married & $\begin{array}{c}-.008 * * \\
(.001)\end{array}$ & $\begin{array}{l}-.005^{*} \\
(.003)\end{array}$ & $\begin{array}{c}-.010 * * \\
(.003)\end{array}$ & $\begin{array}{c}-.003 * * \\
(.001)\end{array}$ & $\begin{array}{c}-.003 * * \\
(.001)\end{array}$ \\
\hline $\mathrm{N}$ & 475,974 & 127,790 & 75,505 & 87,141 & 120,601 \\
\hline $\mathrm{R}^{2}$ & .218 & .068 & .029 & .017 & .005 \\
\hline $\begin{array}{l}\text { Mean of Dependent } \\
\text { Variable }\end{array}$ & .085 & .085 & .168 & .038 & .018 \\
\hline $\begin{array}{l}\text { p-value: Coefficients on } \\
\text { POST } 1 * \text { INCENT, } \\
\text { POST } 2 * \text { INCENT equal }\end{array}$ & .219 & .548 & .545 & .208 & .174 \\
\hline
\end{tabular}

POST1 refers to the period when the TCMs are in place but the incentive is not (3/97-3/99) and POST2 refers to the period when the TCMs and incentive are in place (4/99-6/02). INCENT=1 if the claim has an incentivized injury. Each regression also includes year and month dummy variables and injury fixed effects (five-digit ICD-9 codes) as well as employer characteristics (experience rating and method of rating); 1-digit industry; and TCM fixed effects. Standard errors are clustered by injury (five-digit ICD-9 code). Test statistics are from Wald tests. Linear probability models are weighted by the inverse probability a claim has valid return-to-work information.

* Indicates significance at the ten percent level

** Indicates significance at the five percent level 